\title{
CREATING ORGANIC THREE-DIMENSIONAL STRUCTURES FOR PEDESTRIAN TRAFFIC WITH RECONFIGURABLE MODULAR ‘TRUSS-Z’ SYSTEM
}

\author{
MACHI ZAWIDZKI \\ Research Center for Advanced Science and Technology, The University of Tokyo, Japan.
}

\begin{abstract}
This paper introduces the concept of an innovative truss system (truss-Z) that allows the creation of complex and re-configurable structural networks with certain organic aesthetics. The system is composed of two modular units used for constructing the main structure of the truss and a single module for the supporting structure. An example is given of the use of the system to provide pedestrian walkways, which allows the connection of any given number of points in space (terminals). It also permits the creation of loops and multiple branches of the structure. The geometry of the truss- $Z$ is based on a universal module which, subject to geometrical transformations, allows the construction of structural links along virtually any 3D paths. Scale models of the modules are created from resin cast using two types of mold and timber using an aluminum template. Various algorithms for local and global discrete optimization of the modular structure are proposed. A number of cases of creating a truss network in a constrained environment are discussed. The elements of the environment model real obstacles such as roads, buildings, and watercourses that may constrain both the run of the truss and the placement of the supports. An example of a truss- $Z$ network connecting six terminals in an environment with three obstacles is shown. The issues of fabrication of the modules of the truss, full-size manufacturing, and joinery are also discussed.

Keywords: 3D, emergence, modular, organic, overpass, reusable mold, template, truss system.
\end{abstract}

\section{INTRODUCTION}

The motivation for this project was to develop a universal structural system allowing the inexpensive construction of any three-dimensional path for pedestrians as shown in Fig. 1. A single segment of the truss system can link efficiently any two terminals in space as shown in Fig. 2. The system also allows for the branching of segments and the construction of spirals and closed loops. Structural strength is achieved by combining the frame and truss rigidity.

Due to modularity, the system is potentially inexpensive. Every run of the truss is composed of only two modular elements which can be prefabricated or constructed from locally available materials using a template system. In both cases the system promotes sustainability - either by possible minimization of the embedded energy or by reducing the cost of the transportation as well as the carbon footprint. The assembly of the modules may also be possible without the necessity for heavy equipment. The support system of the truss is based on a single member. The geometry and other properties of the units can be modified to accommodate different purposes such as ventilation ducts, reinforcing structures, cycle paths, etc.

Many truss structures of complex geometry have been erected [1], however almost always they are composed of non-standard members. The free-form shapes usually require high levels of customization where many members need to be individually prefabricated or adjusted [2]. Available systems composed of simple modules or members offer very limited spatial diversity of the overall form [3-5]. The simple forms are a result of the assembly of simple units. Such an approach makes it impossible to create any truly free-forms. Unlike other modular systems [6], the unit module of the truss- $\mathrm{Z}$ is not overly simplified, and even the simplest forms are constructed by the assembly of two types of modules. Truss- $Z$ allows for a wider variety of spatial configurations and the assembly of the same modules often results in the emergence of an organic form.

(C) 2013 WIT Press, www.witpress.com

ISSN: 1755-7437 (paper format), ISSN: 1755-7445 (online), http://journals.witpress.com

DOI: 10.2495/DNE-V8-N1-61-87 


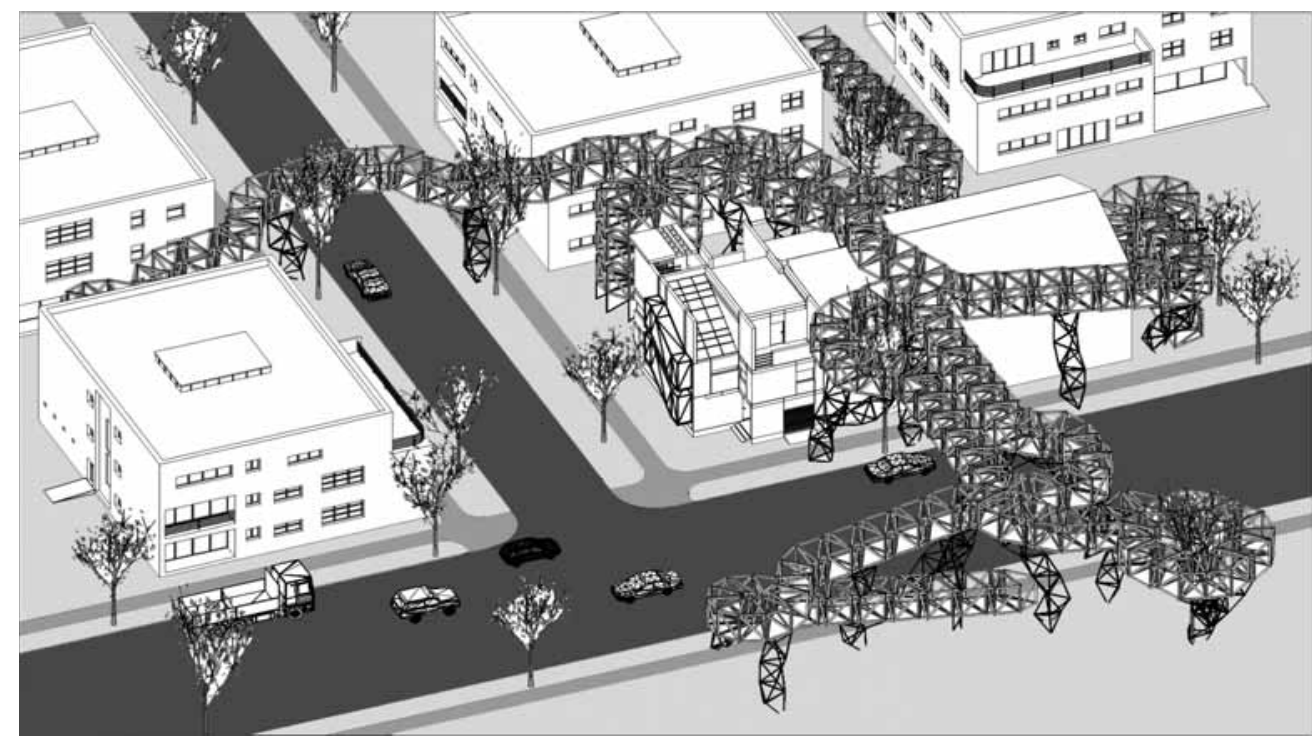

Figure 1: A conceptual example of a truss network constructed with the truss-Z system.
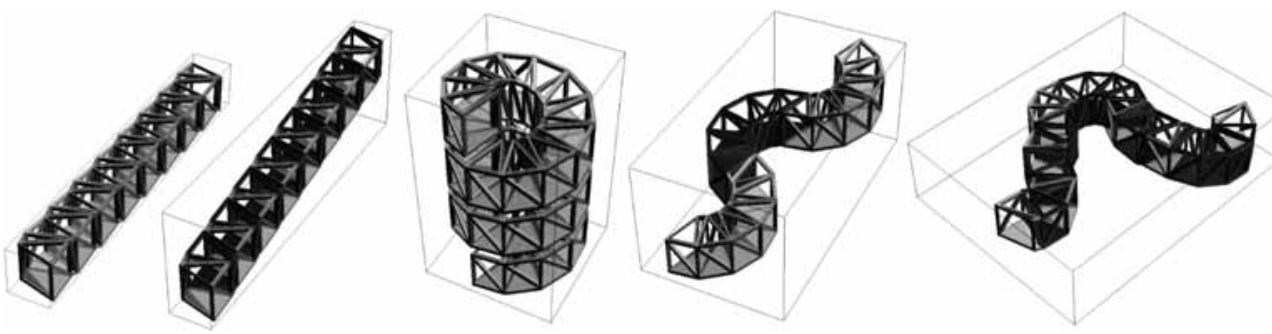

Figure 2: From the left: a straight run, a slope, a spiral, three simple compounds, and a free-form.

A number of theoretical projects described in literature claim modularity in a topological sense, where in fact each 'module' has different geometry [7]. The concept of modularity presented in this paper refers to geometrical modularity, that is, the unit modules are identical in the geometrical sense.

The problems of physical realization of the system were also considered. A number of practical issues including the joinery and assembly of the modules into the structural path were addressed while examining various methods of fabrication of the truss modules.

\section{THE GEOMETRY OF THE MODULE}

The essence of the truss- $Z$ is the module, which in a certain sense is biomimetic. In natural systems, complexity often arises from the interactions of a few, relatively simple but non-trivial elements or agents. In case of truss-Z, the universal module has a certain degree of complexity which allows the creation of structures with high levels of emergent complexity.

Since the system in this case is meant to provide pedestrian walkways, the geometry of the modules is highly constrained by specific requirements [8]. The vertical angle of the module at the axis 

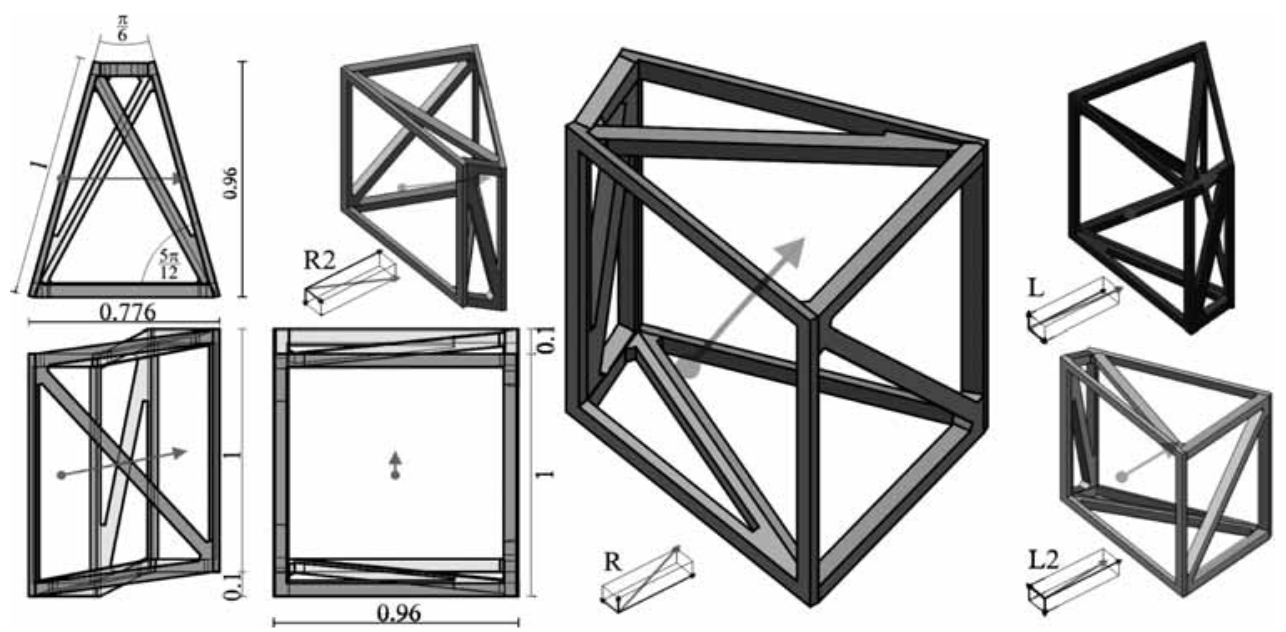

Figure 3: The geometrical properties of the module and all its variations: R, R2, L, and L2.

is $11.31^{\circ}, 8.05^{\circ}$ at the long, and $27.80^{\circ}$ at the short sides. The horizontal angle of the unit is $30^{\circ}$, therefore a complete right angle turn can be completed with only three units, which combined with the vertical angle, allows the creation of a vertical spiral. Some examples of various spatial configurations are shown in Fig. 2.

The main truss of the system is composed of only two types of modules, which are named according to the 'right-hand grip rule': R (right) one 'turns left and goes up' and L (left) one that 'turns left and goes down'. The $\mathrm{L}$ and $\mathrm{R}$ units are mirror reflections. When the $\mathrm{R}$ unit is rotated along the vertical axis by $150^{\circ}$ it is then called $\mathrm{R} 2$ (rotated right) and the rotation of the L unit becomes an L2 (rotated left) respectively. L2 and R2 are also mirror reflections. All these variations have different vectors equivalent to the change of the position in space: 'up and left' (R), 'up and right' (L), 'down and left' (R2), and 'down and right' (L2) as shown in Fig. 3.

\section{FABRICATION AND MANUFACTURING OF SCALE MODELS OF THE MODULES}

According to common understanding, 'design' is a process of inventing physical objects that display new physical order, organization and form, in response to function [9]. Producing a physical model from a 'virtual' one is an essential stage in architectural or engineering design [2]. Fabrication of a scale model can be considered as an important verification during the design process and a major step toward the production of final, full-scale objects. Although it has always been a core part of the design, due to recent developments of new tools and the growing complexity of geometries generated in CAD programs, producing physical models of designed 'virtual' objects has become even more common. For example, in the automobile and aerospace industries, rapid prototyping has been an integral part of the design process for over 15 years [10]. Recently the architecture profession has also started to use these techniques in the design process [11], for instance Foster \& Partners' rapid prototyping department produces approximately 3,500 models per year [12].

It was decided to physically model the truss- $Z$ module in $1: 35$ scale. Since it is a modular system, it was more practical to produce several identical units than models of complete examples of the truss structures. In this way various configurations could be demonstrated and their functional and structural feasibility could be examined. Most importantly, the structures could be reconfigured and further analyzed. Moreover, making a model that could efficiently convey the concept required a large 

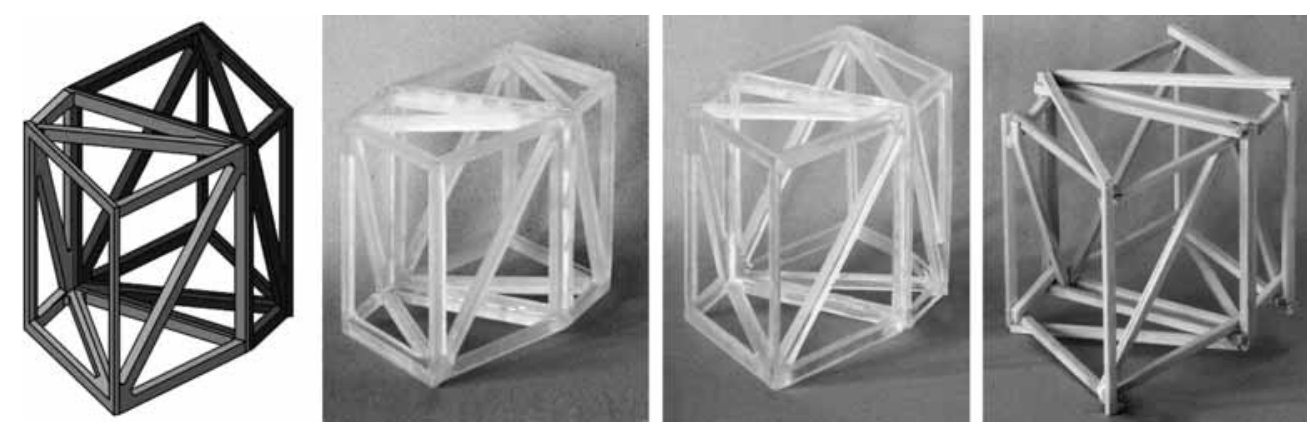

Figure 4: Two modules put together: (1) an isometric view of a computer model; photographs of: (2) a 3D print (by Eden 250 by Objet Geometries Ltd.) (3) a resin cast, (4) a wooden model.

number of units as shown in Figs. 1 and 16, thus the fabrication should be as easy and inexpensive as possible.

The unit represents a class of 3D shape which cannot be produced by a single extrusion. The fabrication of the units is discussed in two contexts: inexpensive and efficient making of a scale model and future full-size manufacturing.

Two methods were demonstrated: an innovative method of casting the structural units from resin using a silicone rubber mold system and a method of assembling and gluing wooden bars using a metal template. Figure 4 shows two modules produced by various methods.

\section{RESIN CASTING WITH A REUSABLE SILICONE RUBBER MOLD SYSTEM}

Since preparing the model of the truss required several units of only two kinds, a mold for resin casts was an interesting alternative. In general, however, casting has a major limitation - if the mold is to be reusable, the produced shapes are a result of a simple extrusion. As mentioned above, the entire unit cannot be produced in a single extrusion; therefore, it was analyzed and divided into extrudable parts. Moreover, due to the geometrical complexity of the unit and the fact that it must be possible to separate the cast from the mold safely a number of times without damaging either of them, the creation of the mold was challenging and resulted in a fairly complex six-part system as shown in Fig. 5.

\section{ALUMINUM 'NEGATIVE' MOLD}

Due to the high slenderness of the truss members, the unit module is rather fragile. To avoid problems with separating the cast from the mold, a non-rigid material such as silicone rubber was used. A 'negative' form to make the silicone rubber mold was designed and fabricated as shown in Fig. 6.

Most of the parts for the negative mold were cut from $1 \mathrm{~mm}$ and some from $3 \mathrm{~mm}$ aluminum sheet: two elements were cut from $4.38 \mathrm{~mm}$ and four from $7.5 \mathrm{~mm}$ aluminum. After assembling, the molds were filled with a commercially available silicone rubber and the 'positive' forms were created as shown in Fig. 7.

RTV Silicone Rubber KE-17 by Sin-Etsu Chemical Co., Ltd. was used, due to the proper workable time, viscosity before curing and the curing time. The procedure was as follows: the curing agent of which a standard amount was $0.5 \%$ to the base silicone rubber was added to the required amount of the base silicone rubber. The mixture was mechanically stirred for 5 minutes. To thoroughly remove air bubbles, the mixture was subjected to a vacuum chamber for 30 minutes. Afterward, the mixture was gently poured into the 'negative' molds. In the case of the aluminum molds, a releasing agent was used on their surfaces. In the case of the 3D printed molds, it was not necessary. The molds 


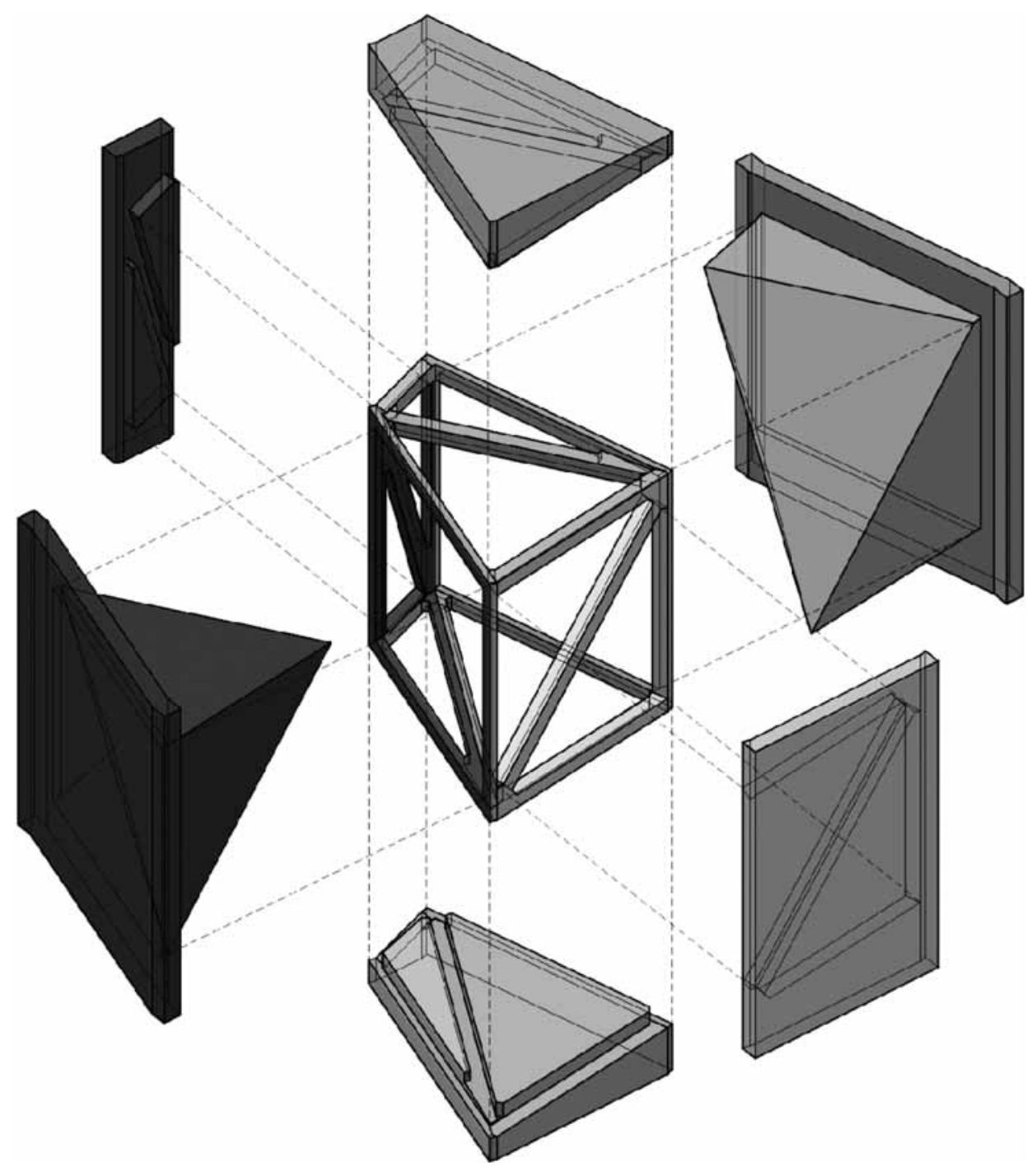

Figure 5: An isometric view of the CAD model of the mold and a resulting cast.

were left to set overnight. After curing, the silicone rubber 'positive' molds were removed from the 'negative' molds.

For the cast material the 'Crystal Resin' by Nissin Resin Co., Ltd. was used. The properties of the resin are: low viscosity for good penetration of the mold (approximately $1000 \mathrm{mPa} \cdot \mathrm{s}$ ), comfortable workable time $\left(60^{\prime}\right)$, and required strength. This material consists of a base liquid epoxy resin and a curing agent. The curing agent of which the ratio to the base liquid resin is 50 to 100 was poured into the base liquid resin, and the mixture was well stirred. Material was injected slowly from the lowest point of the mold using a syringe. For the first hour of setting the resin inevitably leaks (mostly into the spaces among the six-part mold) due to fact that the pieces of the mold were made independently, so an additional small tank was installed at the highest point of the mold (Fig. 9). The excess of resin residue (20\% in addition 


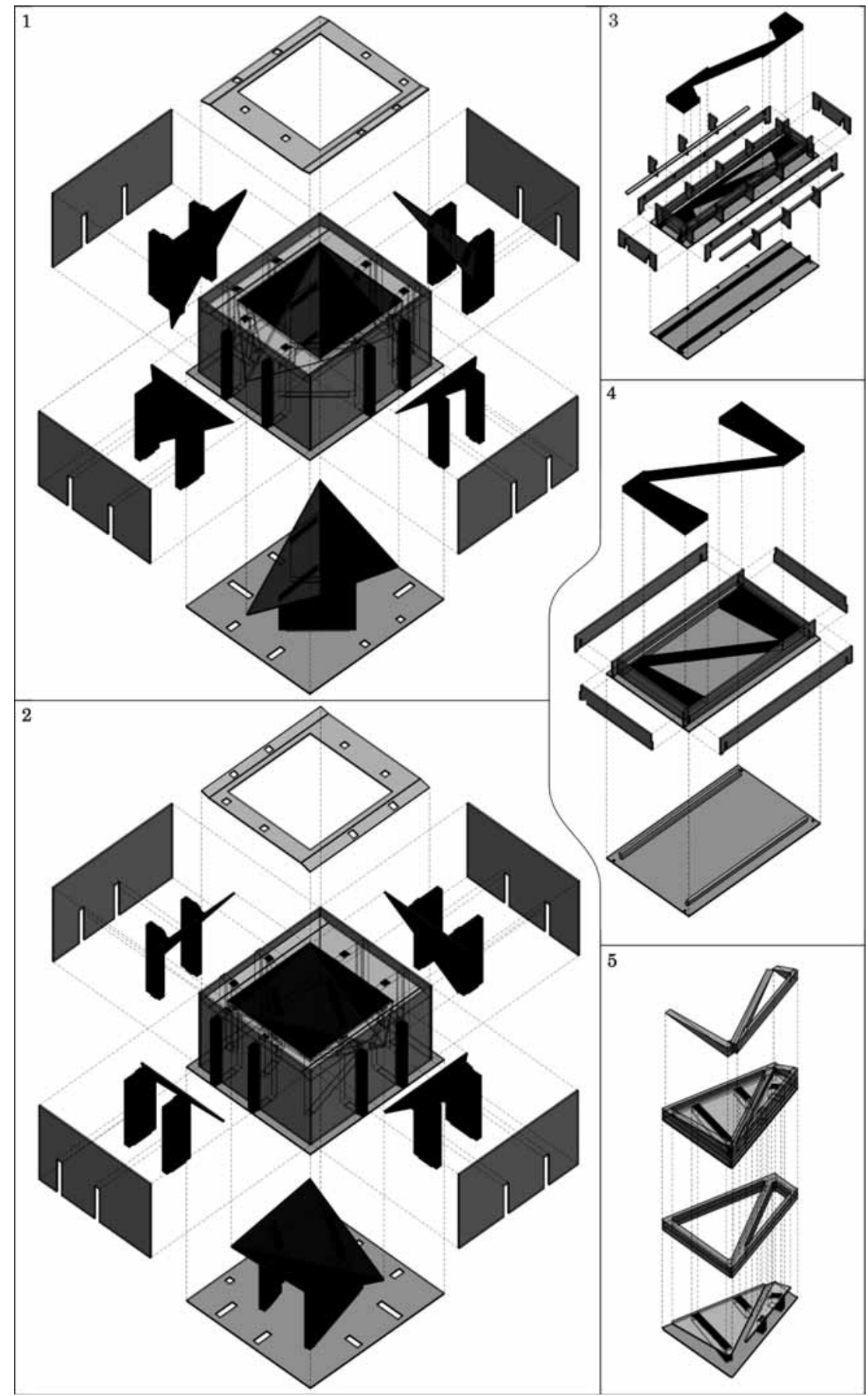

Figure 6: The assembly diagram of the 'negative' mold made of aluminum plates. 

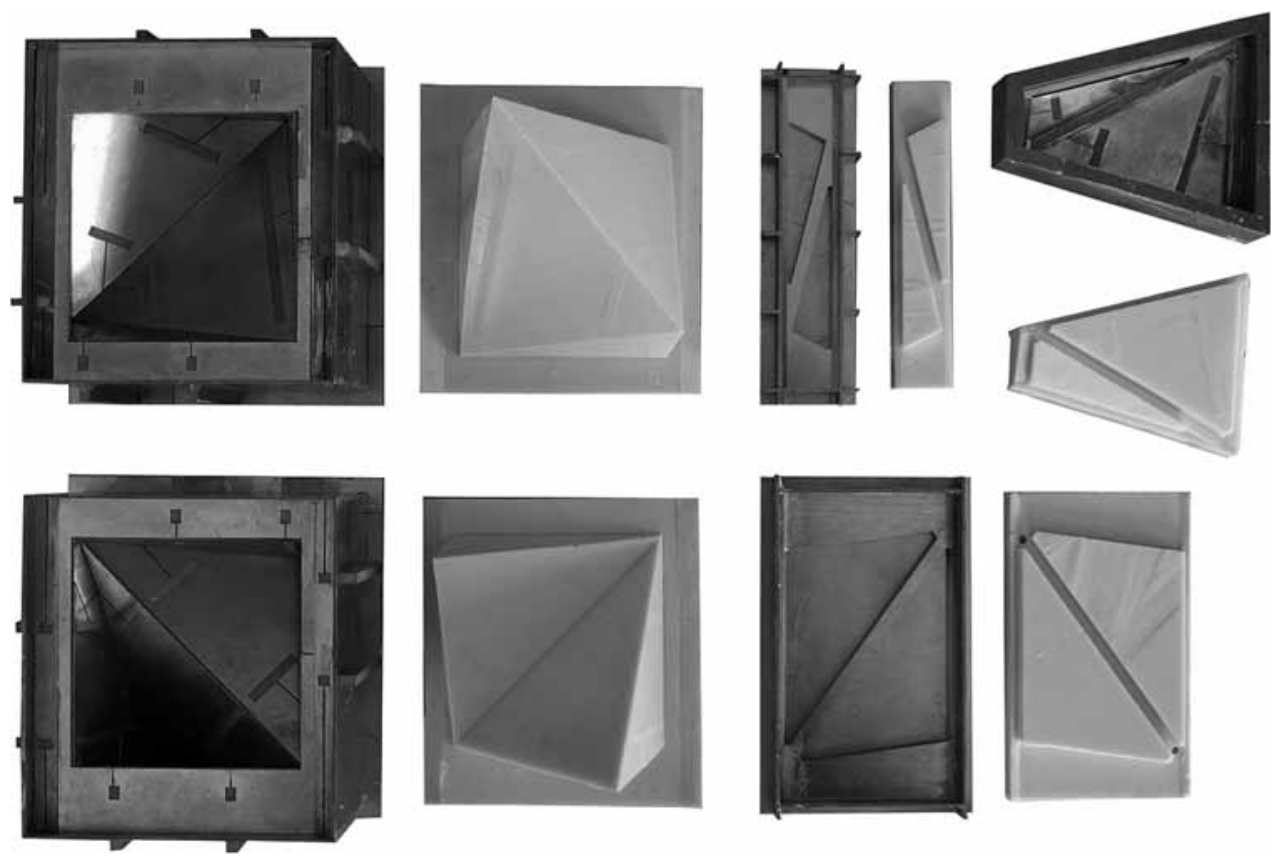

Figure 7: The aluminum 'negative' molds and resulting silicone rubber forms that were used as molds for resin casts.

to the theoretical volume of the cast) was left over in that tank making certain that no air bubbles returned inside the mold. During the first hour after injection, most of the resin from the tank gradually returned to the mold. The cast may be removed safely from the mold after 12 hours (although the full curing takes up to 36 hours) and while still a little soft, the excess of resin can be cleaned off from with a sharp cutter or scalpel. The casts can be tinted with coloring agents for epoxy resin which are readily available from manufacturers; alternatively a colored liquid resin, such as urethane can be used.

\section{3D-PRINTED 'NEGATIVE' MOLD}

Every module can be produced by a 3D printer as shown in Fig. 16. The advantage is the speed - a matter of hours, depending on the machine, and the geometry which can be almost flawless. Although this seems the simplest way, it has also certain disadvantages: very high cost and often unsatisfactory strength, which is lower than that made of a regular resin, although comparable with those made of wooden bars. Also, higher the strength, higher the price of the material. Another possible disadvantage is the limitation of the size of a printed object. Therefore a rational choice was to use this technology for making molds for multiple resin casts.

Taking advantage of the 3D print technology and aiming to produce the units inexpensively, a 'negative' mold for the silicone rubber mold to be used for resin casts was 3D-printed with uPrint (personal printer by Dimension 3D Printing) with Acrylonitrile Butadiene Styrene (ABSplus) resin of strength of approximately $30 \mathrm{MPa}$ as shown in Fig. 8.

After casting the 'positive' molds from these 3D-prints from silicone rubber, the final resin casts were produced in the same way as before. Due to fairly low vertical resolution of the print (the layer thickness $=0.254 \mathrm{~mm}$ ), the 'handmade' aluminum molds produced smoother surfaces with less internal leakage between the parts of the mold as shown in Fig. 9. 


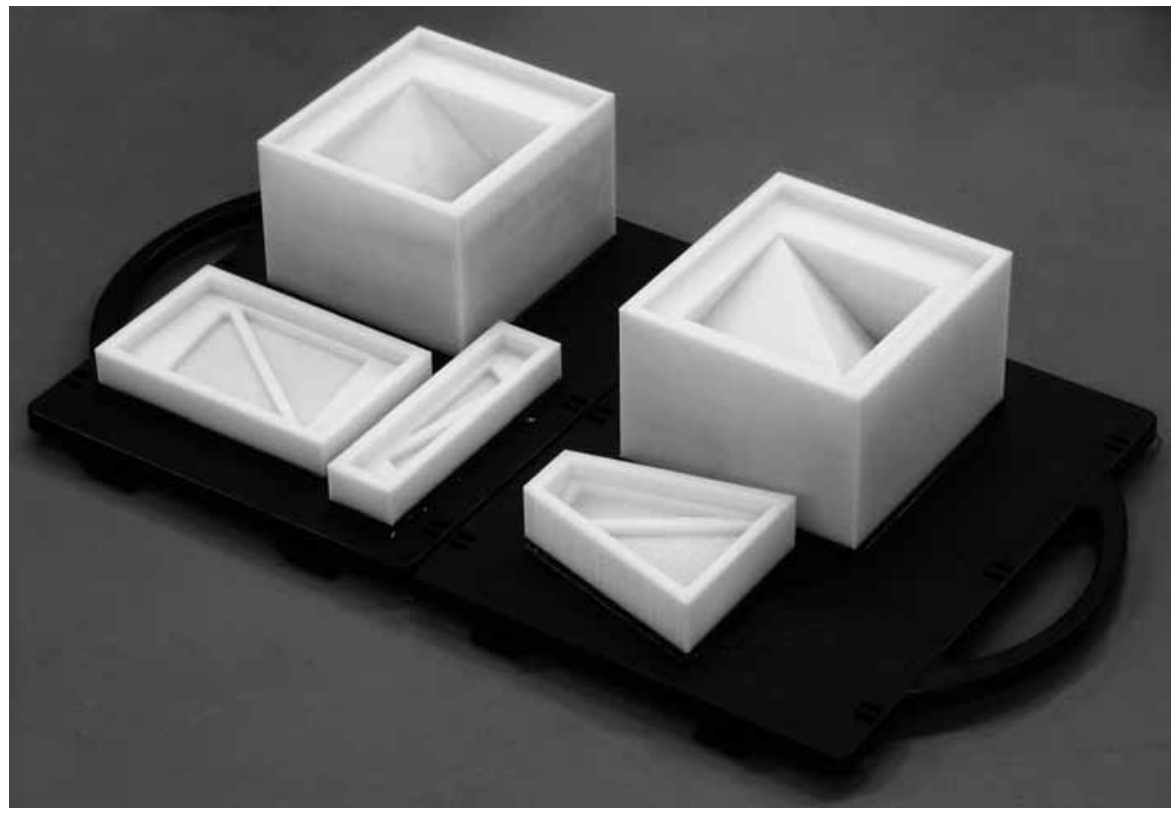

Figure 8: A photograph of the 3D-printed 'negative' mold.

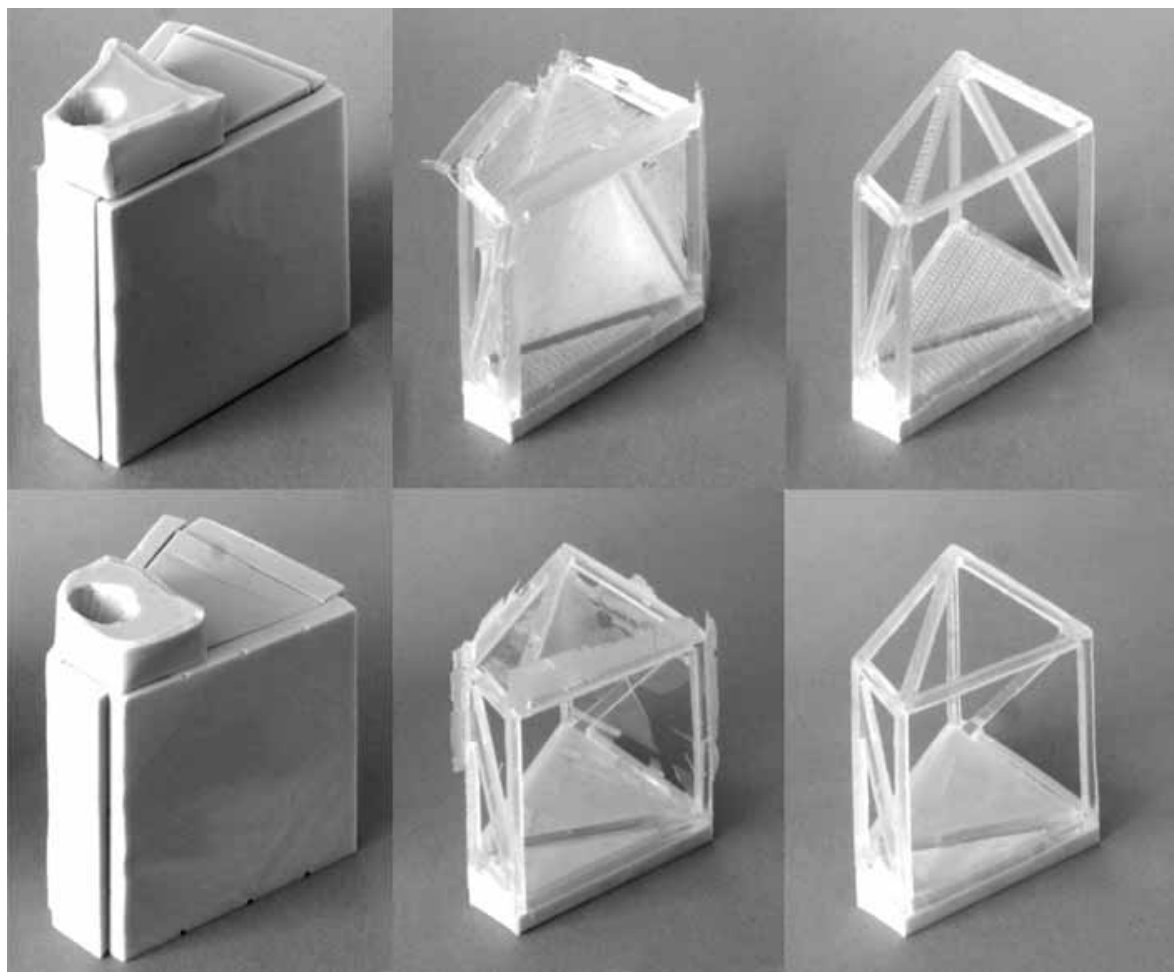

Figure 9: A comparison between the silicone rubber molds made from a 3D print (top) and aluminum plates (bottom.). From left to right: a closed mold, resulting raw cast, and a cleaned cast. 
7 ASSEMBLING BARS USING A TEMPLATE SYSTEM

Although the resin casting method has a certain conceptual elegance, a more traditional approach of making the units with simple bars offers a number of practical advantages:

- The units can be made of a variety of materials.

- In the manufacturing of the full size units, locally available or recycled materials can be used.

- The truss members can be recycled as well.

- The geometry of the unit can be adjusted.

- It is a well established method; therefore, a number of practical issues are already solved.

The most intuitive material to be used in this method is wood (timber). There is a great tradition of timber joinery both in the East and in West. Nevertheless the great majority of common timber joints are perpendicular, which is not the case here, where most of the members meet at a non-right angle usually and often are not even coplanar.

\section{THE METAL TEMPLATE}

To produce a number of possibly identical units made of wooden bars, a metal template was designed as shown in Fig. 10.

The template was meant to be reusable. All the plates of the template were cut from $2 \mathrm{~mm}$ aluminum sheet using a wire-cut type Electric Discharge Machine (EDM) and assembled using a 2-part epoxy adhesive. Since elements of the templates for the two modules are symmetrical, to avoid confusion, special markings were cut on all of the elements. This greatly facilitated the later process of making the trusses. The process of assembling a wooden module using the template and opening the template is shown in Fig. 11.

A number of model units were produced by gluing wooden bars using this template system. With some practice and patience the quality of modules came to be very high regarding both strength and aesthetics. Making of one approximately $10 \times 10 \times 10 \mathrm{~cm}$ unit took about 45 minutes. For making full size modules to maintain good geometrical accuracy, a similar concept of a template seems very practical and rational.
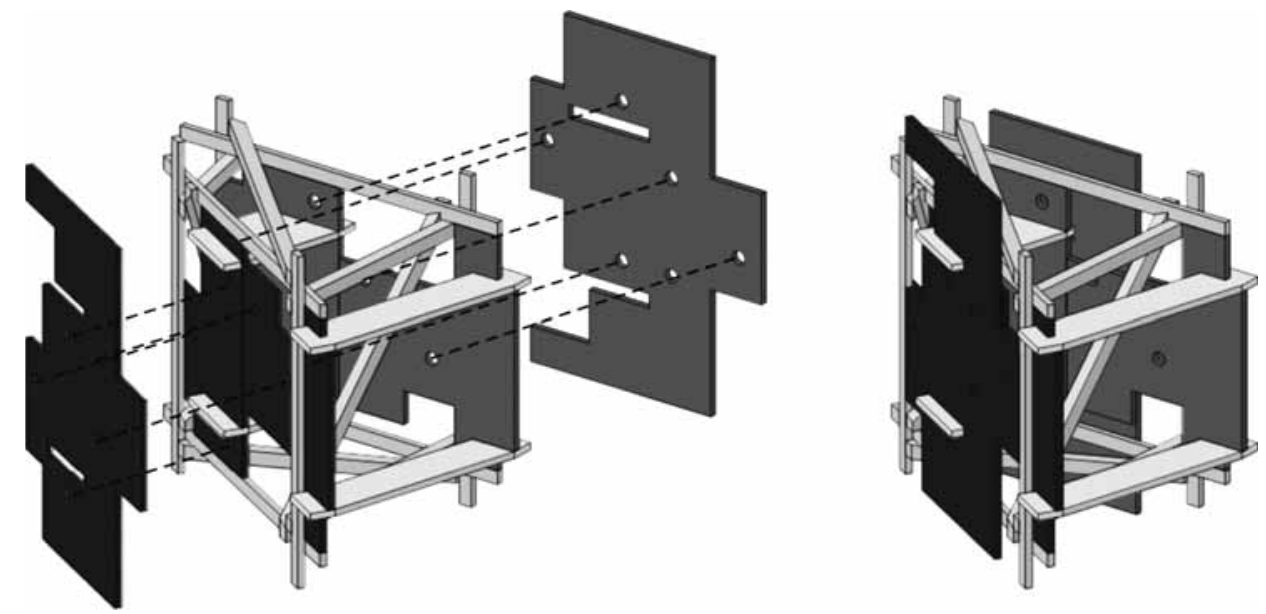

Figure 10: Two isometric views of the CAD model of the template and a bar unit (shown in light gray). On the left - open template; on the right - closed template. 


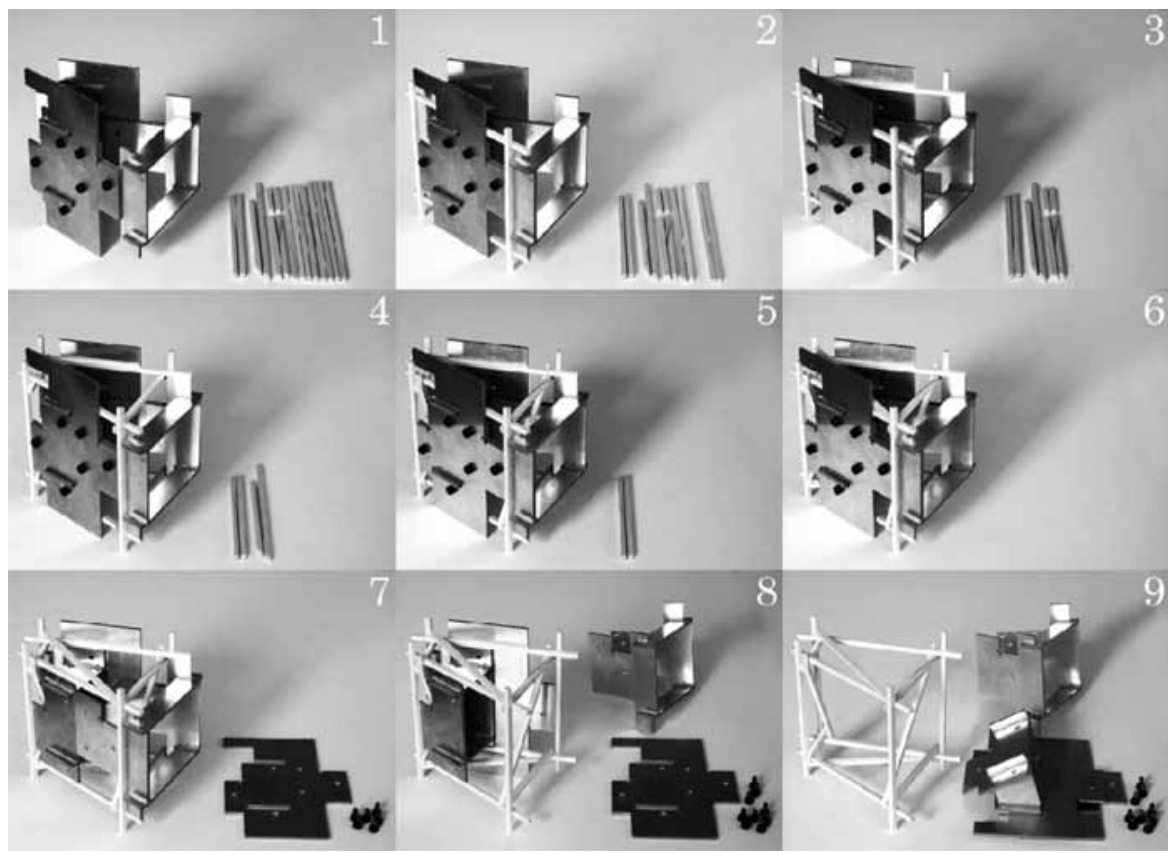

Figure 11: The photographs 1-6 show the sequence of assembling the wooden truss module; the photographs 7-9: the sequence of opening the template. The wooden bars are trimmed after assembly.
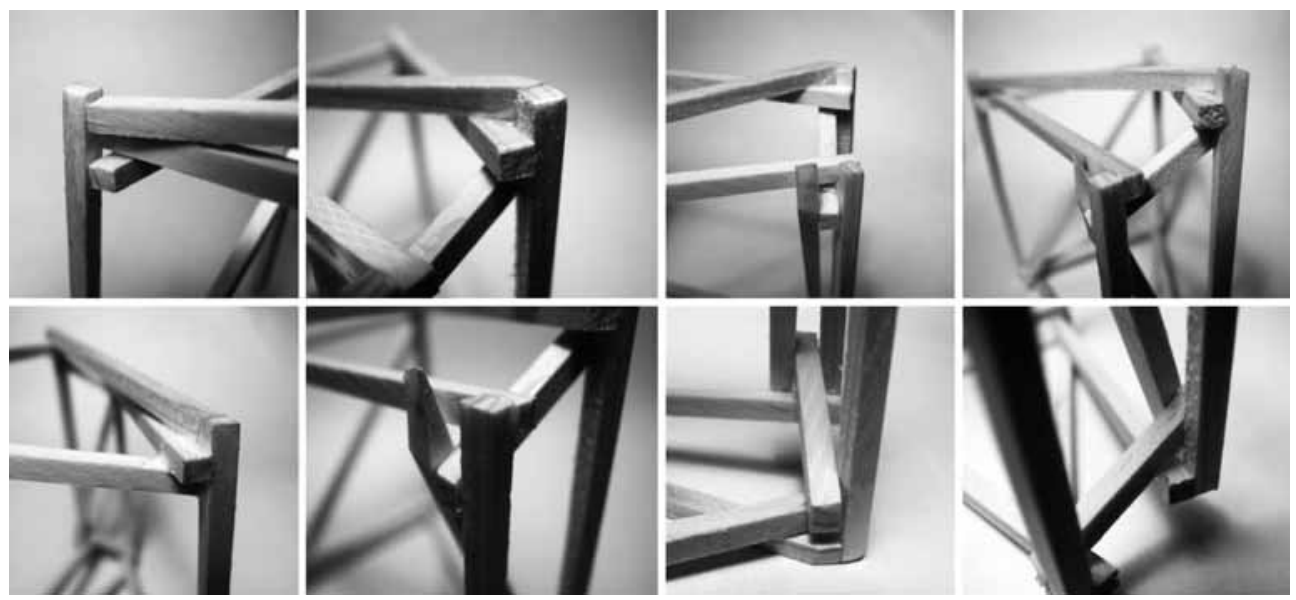

Figure 12: Photographs of joints of a small-scale model.

\section{JOINERY}

For the scale model, the wooden sticks were trimmed in one plane. Due to the size reduction, the glued joints demonstrate proportionally enormous strength; therefore, no additional adjustment to the shape of the members was done as shown in Fig. 12.

The model assembled by such a method is very rigid; however, in the structural units that are 35 times larger such joints are unrealistic. This is a common problem with scale models, and 
Table 1: The main stresses in a simple beam element depending on the scale of a model.

\begin{tabular}{|c|c|c|c|c|}
\hline & Stress in the Function of Scale $s$ & Load & $\begin{array}{c}\text { Geom- } \\
\text { etry }\end{array}$ & The Stress Difference $\Delta$ \\
\hline Bending & $\sigma_{B}[s]=\frac{12 s \cdot z \cdot s^{2} M}{s^{4} a^{2}}=\frac{12(z \cdot M)}{s \cdot a^{2}}$ & $\mathrm{M}=1$ & $\begin{array}{l}\mathrm{a}=1 \\
\mathrm{z}=1\end{array}$ & $\Delta_{B}=\frac{\sigma_{B}[1]}{\sigma_{B}[1: 35]}=s=\frac{1}{35} \approx 0.029$ \\
\hline Tension & $\sigma_{T}[s]=\frac{s \cdot P}{s^{2} a^{2}}=\frac{P}{s \cdot a^{2}}$ & $\mathrm{P}=1$ & $a=1$ & $\Delta_{T}=\frac{\sigma_{T}[1]}{\sigma_{T}[1: 35]}=s=\frac{1}{35} \approx 0.029$ \\
\hline Shear & $\tau_{\text {Max }}[s]=\frac{3 s \cdot T}{2 s^{2} a^{2}}=\frac{3 T}{2 s \cdot a^{2}}$ & $\mathrm{~T}=1$ & $a=1$ & $\Delta_{\tau \operatorname{Max}}=\frac{\tau_{\text {Max }}[1]}{\tau_{M a x}[1: 35]}=s=\frac{1}{35} \approx 0.029$ \\
\hline
\end{tabular}

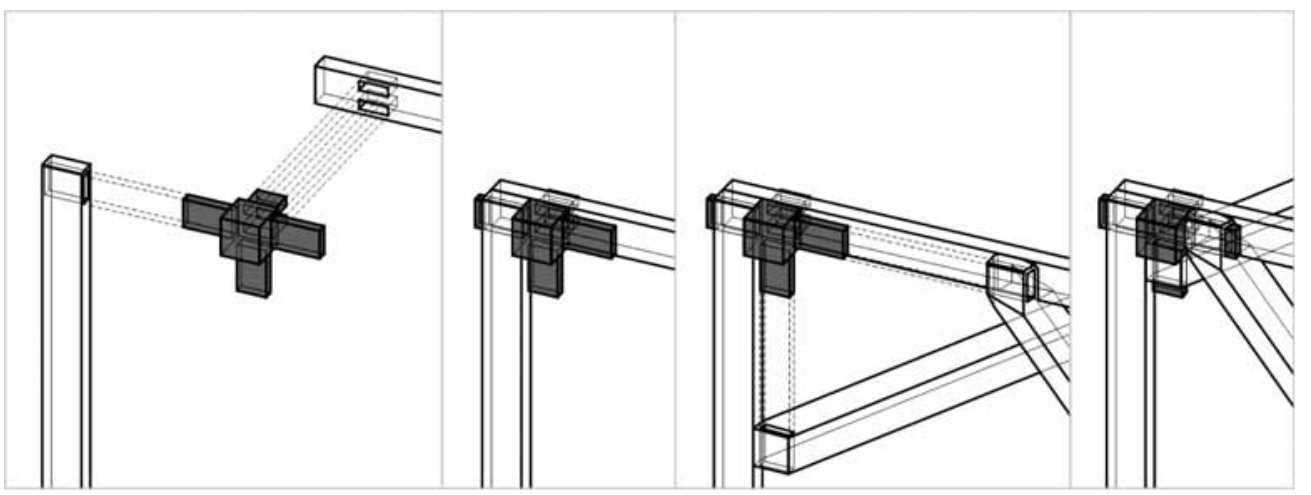

Figure 13: Schematic joinery of a sample joint for the full-scale truss module.

the observations during simple, intuitive experiments of the structural strength may be misleading. To properly represent the element's behavior, not only the forces and dimensions must be reduced proportionally, but also the materials' properties. It is also assumed that the adhesive properties of the glue manifested in the model cannot be practically realized at 35 times larger scale, since it is already the strongest carpenter's glue available.

Table 1 shows the differences of the stresses between the 1:35 scale and 1:1 scale elements for the simplest, linear model for beams.

A possible, realistic joinery system is shown schematically in Fig. 13.

An assembly sequence of one unit using a special joint system is shown schematically in Fig. 14.

\section{COMBINING THE MODULES}

Every two units can be connected in four different ways allowing the creation of any spatial path.

Examples of sequences of the units and the resulting structures are shown in Fig. 15.

A larger example demonstrating various spatial configurations of the truss using wooden-bar modules is shown in Fig. 16.

Moreover, each of the units must be precisely made, since the model will be composed of many units and even a small error multiplied may become a problem. 


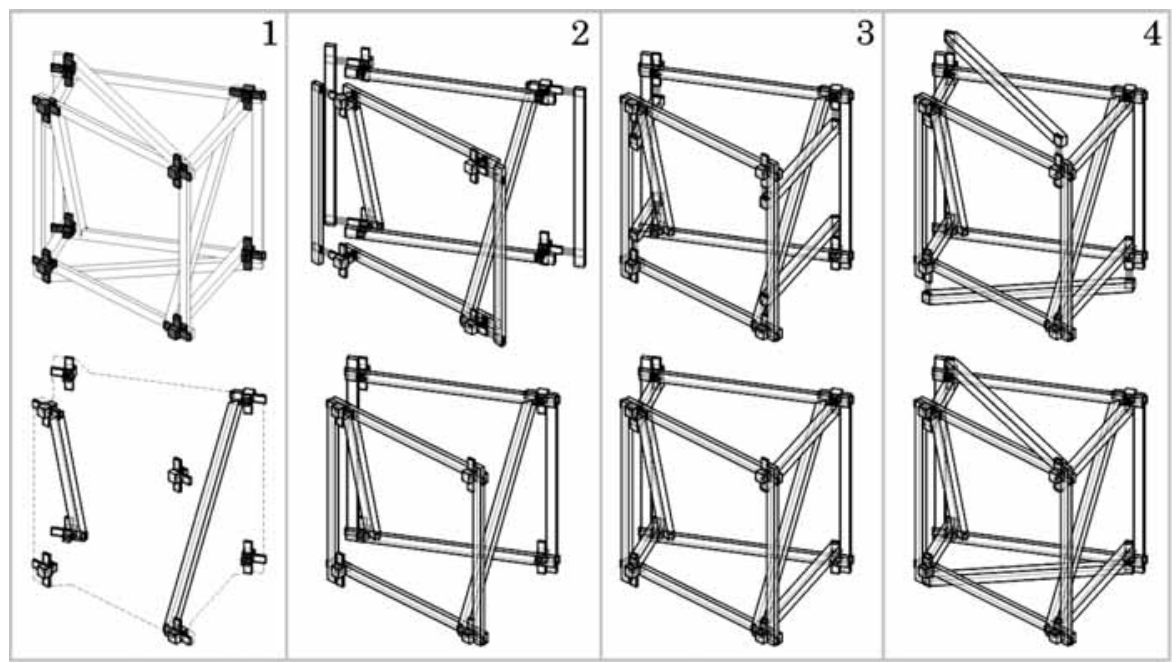

Figure 14: Schematic assembly of one unit with a special joint system.

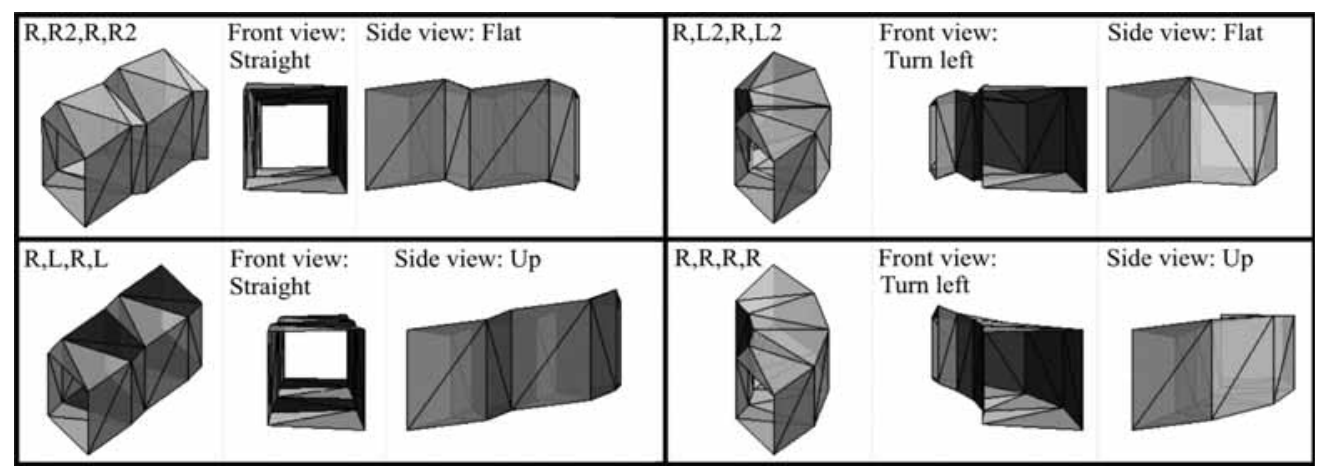

Figure 15: Examples of sequences of units and the resulting spatial structures.

As a result, the fabrication process focused on making the unit trusses as precisely, efficiently, and inexpensively as possible at the university workshop. In this sense, the process differs from a typical rapid prototyping method, where in a similar case the whole truss or a number of sample configurations would be produced, usually using 3D printing as shown in Fig. 17.

\section{THE BRANCHING}

If the number of terminals is more than two, a special way of connecting the modules, by aligning two longer sides of the units, allows the creation of a branching point as shown in Fig. 18.

\section{ASSEMBLING THE MODULES: TRUSS NETWORKS}

For creating the runs of the truss, the following assumptions have been made:

1. The truss must connect any given number of terminals (points in space).

2. The segments of the truss must not collide with any objects including obstacles or other segments of the truss. 


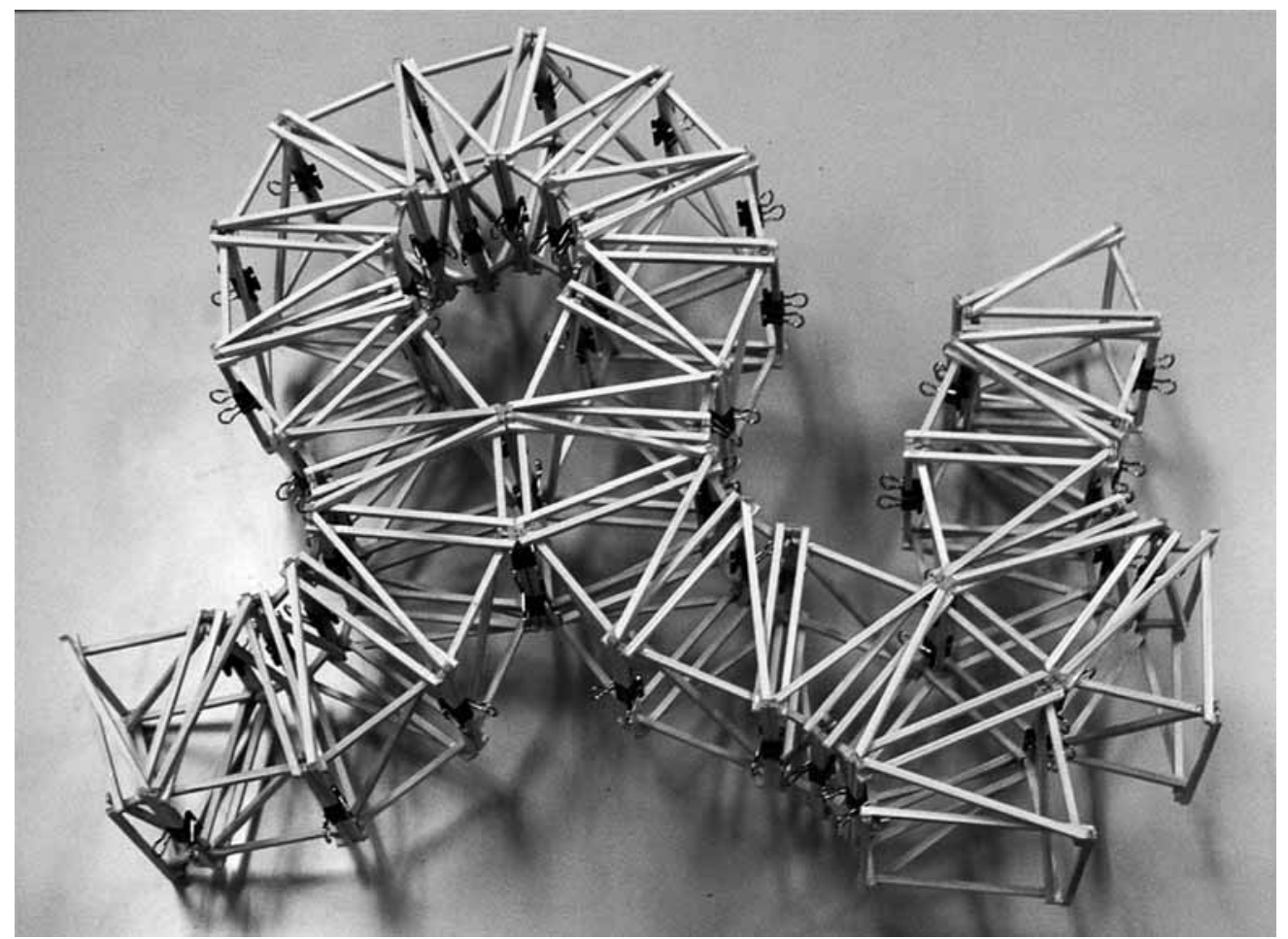

Figure 16: A photograph of a model of a spatial truss network with 28 modules.
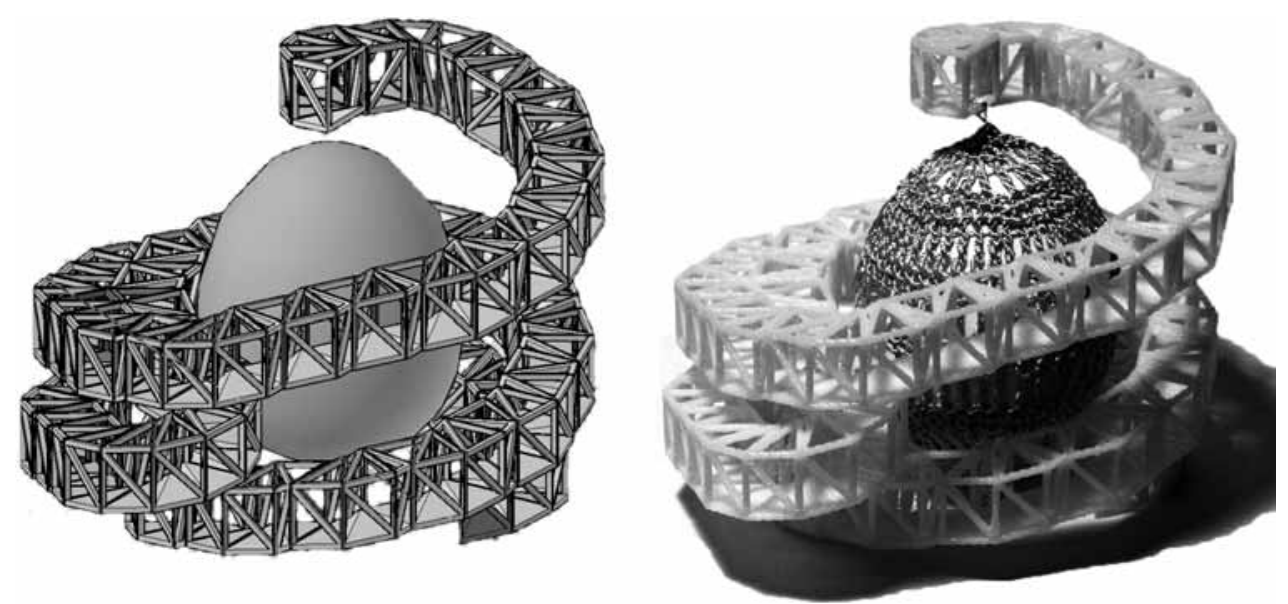

Figure 17: A CAD model and a 3D print of a complete truss network constructed with truss- $\mathrm{Z}$ modules. The suspended Easter egg shows the scale of the object; 118 modules are used. 


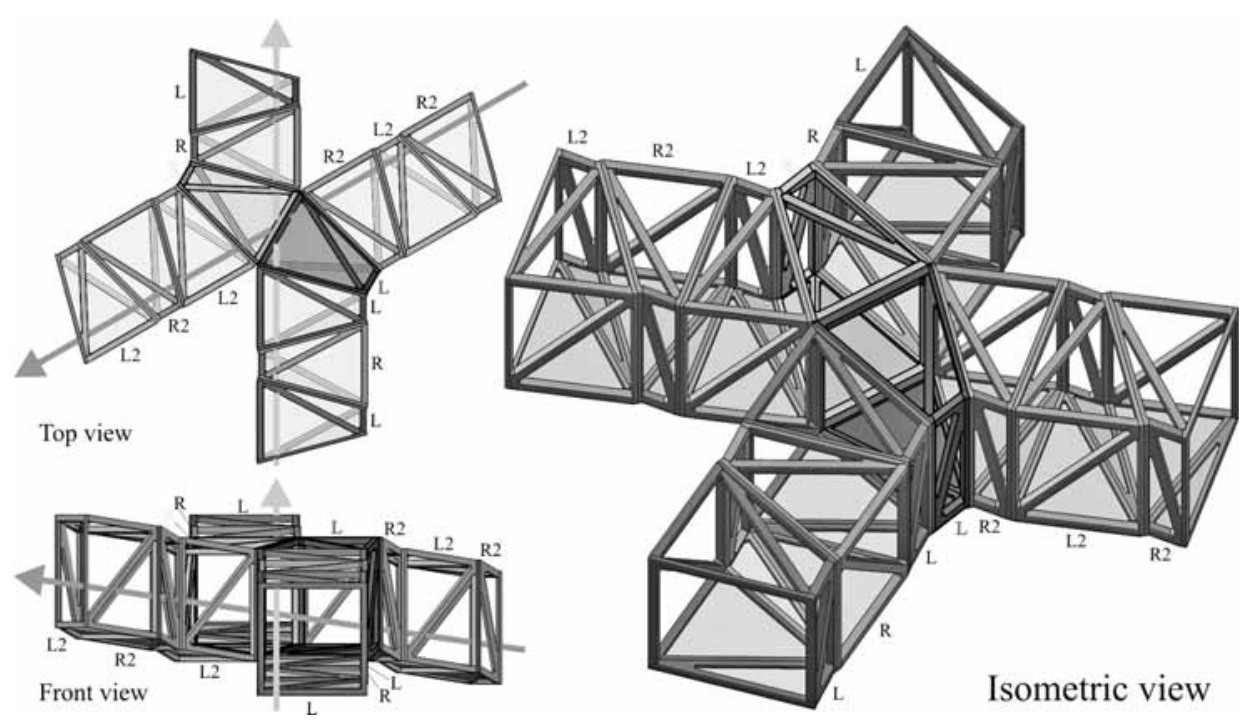

Figure 18: A junction with four branches.

3. The truss should be optimal so that the number of modules used for the structure is kept to the minimum.

4. The network of connections should be made as simple as possible by minimizing the number of additional junctions.

Although the number of junction units is to be minimized, there may be conditions requiring the introduction of redundant junction units as shown in Fig. 19.

The minimum number of junction units $n_{j}$ depends on the number of terminals $n_{t}$ and can be expressed as follows:

$$
n_{i}=\frac{n_{t}+\operatorname{Mod}\left[n_{t}, 2\right]}{2}-1
$$

Two methods of constructing the truss network are demonstrated: alignment to the given paths and a backtrack algorithm.

\section{ALIGNMENT TO THE GIVEN PATH}

Although it is conceptually the simplest way of constructing the truss structure, it certainly is not the most efficient one [13]. However, it exemplifies a number of important issues. The method is based on the presumption that the path in space connecting two terminals and along which the truss to be built is already given. In this method the guide paths are given in the form of 3D splines. At each step, one of four variations of units (two modules and two rotations) that gives the minimum value of the objective function (as shown in Fig. 20) is chosen:

$$
\operatorname{Minimize}\left(\frac{u d}{b}+(1-u)\left(1-v \bullet r^{\prime}(p)\right)\right)
$$




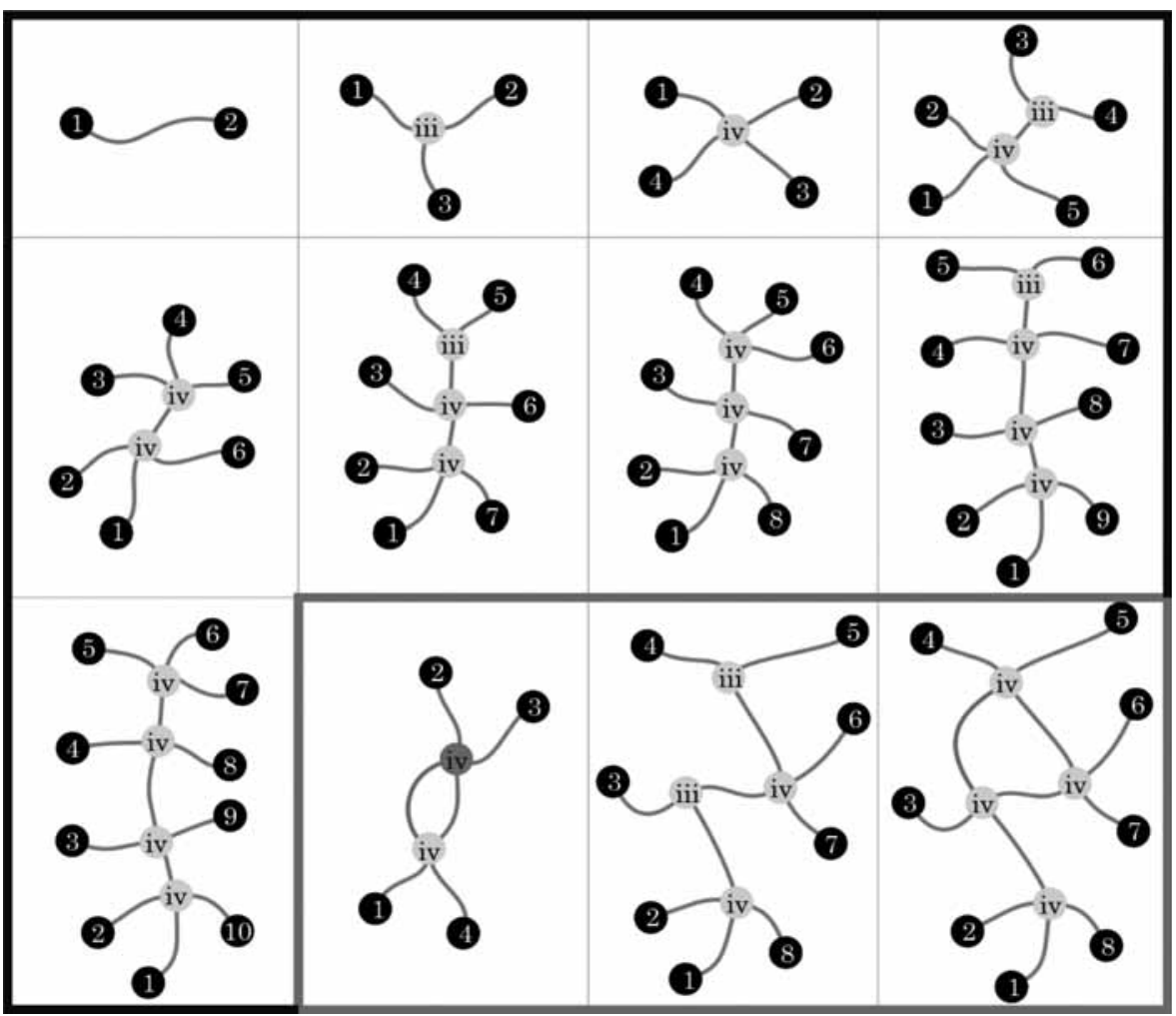

Figure 19: The smallest path networks for a given number of terminals are shown in black from two to ten. The junction units are shown in light gray and the numbers indicate the degree of a node. The three schemes on the bottom right show examples with redundant junction units.
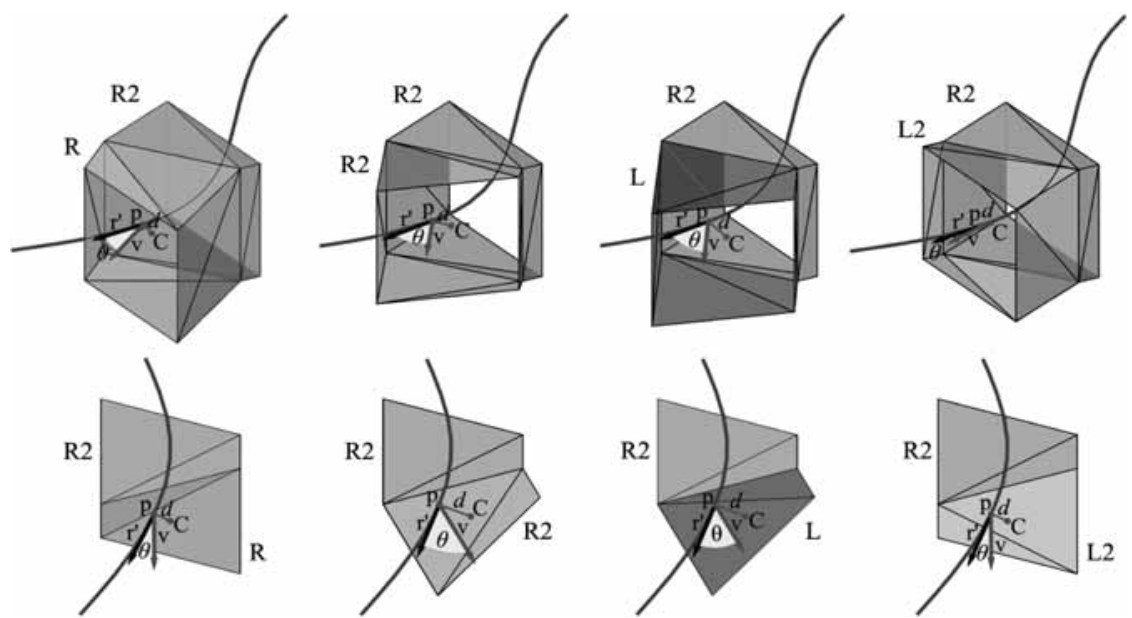

Figure 20: Four possible configurations for the next unit. Top row: isometric views, bottom row: top views. 
where

$d$ is the smallest distance between the centroid $\mathrm{C}$ of a unit and the curve in point $\mathrm{p}$;

$v$ is the vector of the unit;

$r$ ' $[\mathrm{p}]$ is the direction of the spline in point $\mathrm{p}$;

$u$ and $b$ are parameters described below.

The parameter $u$ is a weight ranging from 0 to 1 and moves the influence from the normalized dot product of the direction of the curve and the vector of the unit to the distance between the centroid of a unit and the curve. Since the objective function depends both on distance and angle which cannot be normalized, the parameter $b$ adjusts the ratio between them.

The values of parameters $u$ and $b$ were optimized so the structure closely adheres to the given path and the number of units is minimal as explained in Figs. 21-23 below.

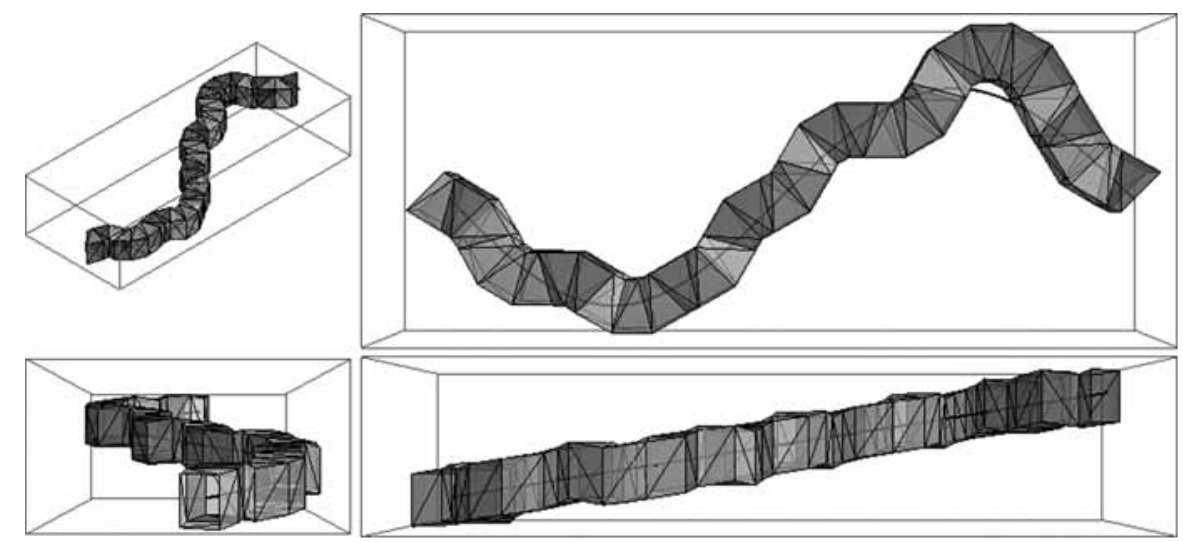

Figure 21: $u=0.5, b=18$; This setting minimizes the distance from the centroid of every new unit to the guide path. As a result, the form of the truss becomes coarse. The structure 'overreacts', which results in an excessive meandering and therefore uses excessive number of modules: 34 . The list of units: $\{R, L, R 2, R, R, R, L, L, L 2, R, R, L, R, L 2, L, L, R, R, R$ 2,L,L,R,R,R,R2,L,L,L,L,L2,L,R,L2,L\}.
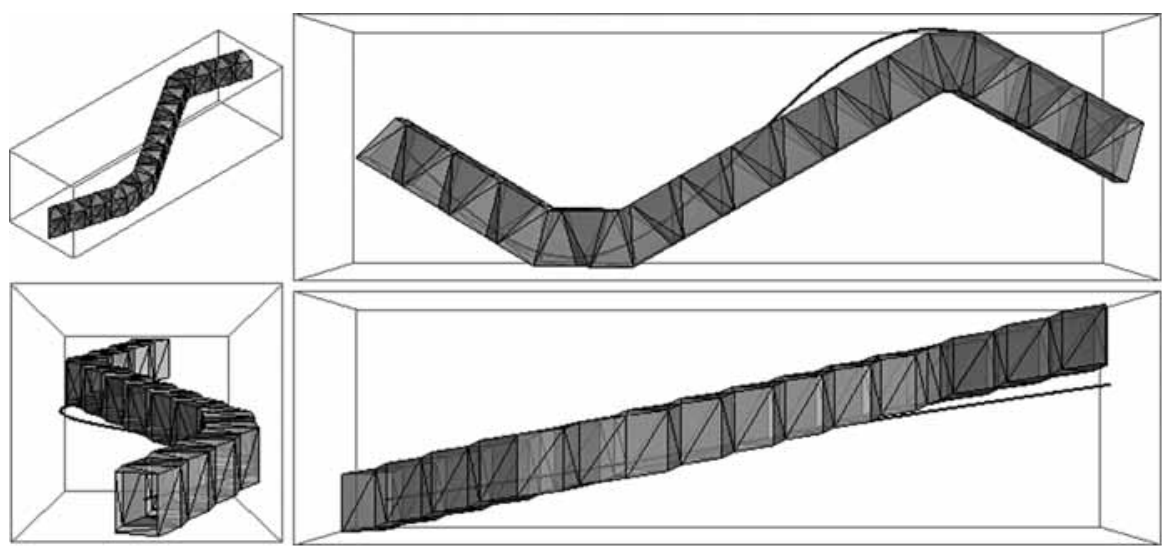

Figure 22: $u=0, b-$ not applicable; Structure is 'smooth' and follows the curvature of the guide path. The smallest number of units used is 29 , but it misses the end point. The algorithm is overly 'relaxed'. The list of units: $\{R, L, R, L, R, L, R, R, L, R, R, L, R, L, R, L, R, L, R, L, R, L, L, L, R, L, R, L, R\}$. 

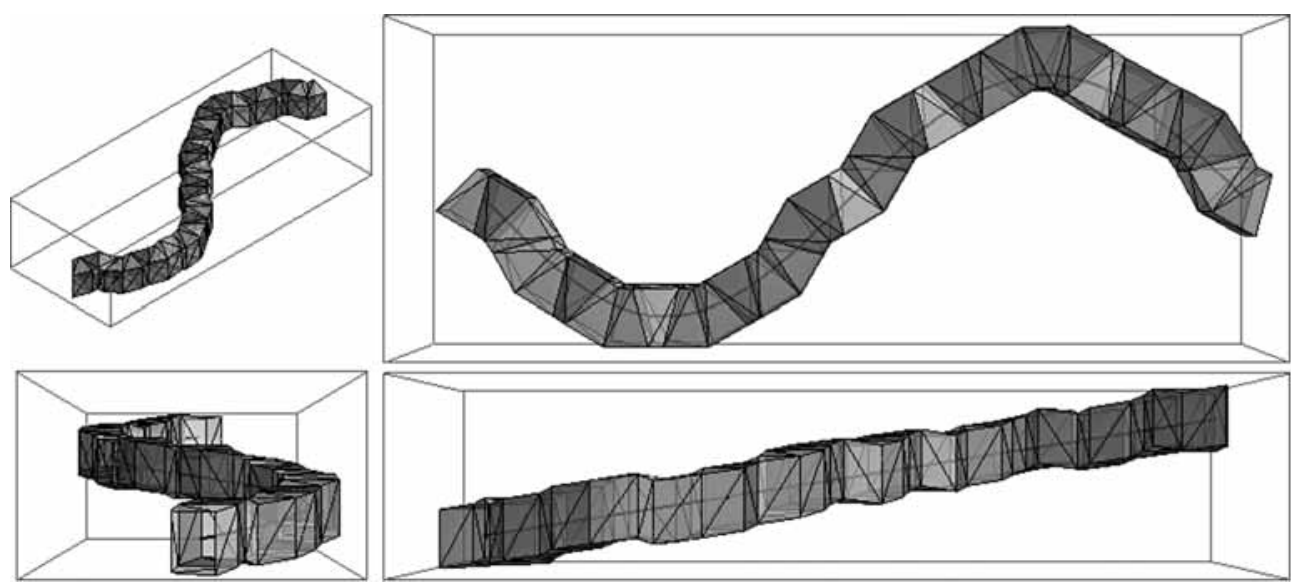

Figure 23: $u=0.5, b=100$; The balance is made between maintaining a small distance to the guide path and following its curvature. The number of units to follow the given path is 33 . The list of units: $\{\mathrm{R}, \mathrm{L}, \mathrm{R} 2, \mathrm{R}, \mathrm{R}, \mathrm{L}, \mathrm{R}, \mathrm{R}, \mathrm{R} 2, \mathrm{R}, \mathrm{R}, \mathrm{L}, \mathrm{R}, \mathrm{R}, \mathrm{L}, \mathrm{L}, \mathrm{L} 2, \mathrm{R}, \mathrm{L}, \mathrm{L}, \mathrm{L} 2, \mathrm{~L}, \mathrm{R}, \mathrm{L}, \mathrm{L}, \mathrm{L}, \mathrm{L} 2, \mathrm{~L}, \mathrm{R}, \mathrm{L}, \mathrm{L}, \mathrm{L} 2, \mathrm{R}\}$.

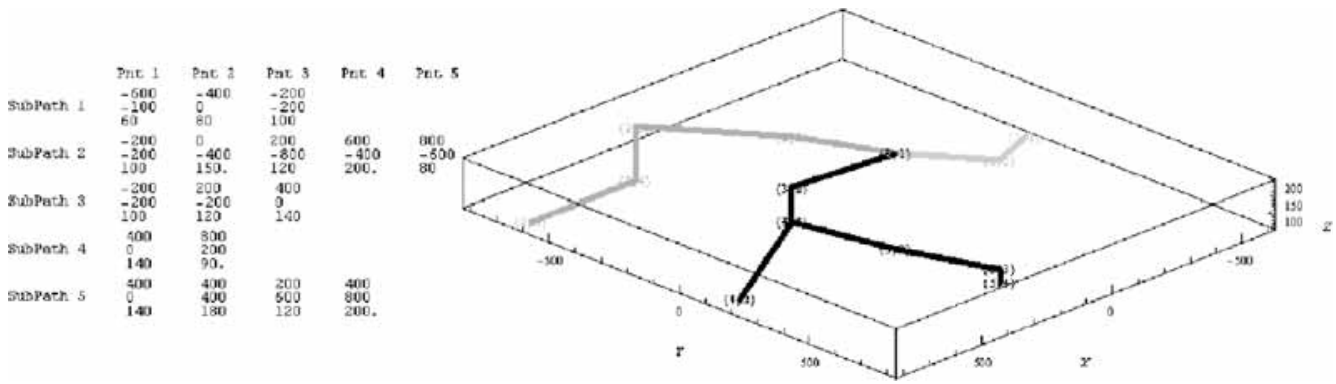

Figure 24: An example of a multi-path truss network composed of five sub-paths. On the left: the list of given points with coordinates, on the right: isometric view.

\section{ALIGNMENT TO A MULTI-PATH}

The algorithm for aligning the structure to the given path operates on a single path as well as a list of sub-paths. The procedure for constructing a truss network with multiple segments consists of the following steps:

1. All the segments of the truss containing two junction points are constructed along the given spline.

2. The junction units are completed by attaching the mirrored units.

3. These units become starting points for the next segments of the truss.

An example of a multi-path network is shown in Fig. 24. The splines along which the segments of the truss are optimized run through the given points. 


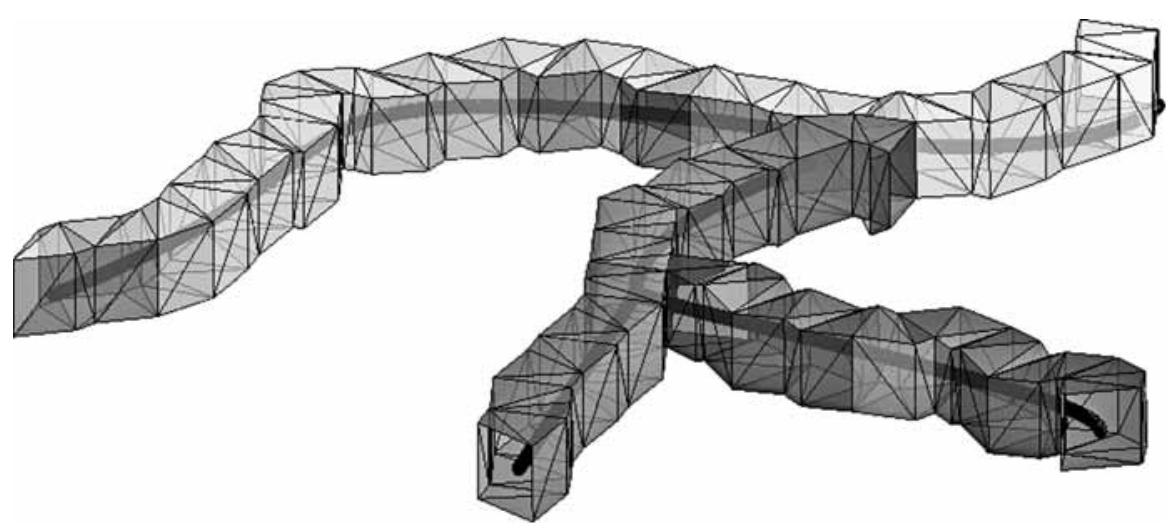

Figure 25: The multi-path network structure generated for the given points in 3D. The splines along which the truss segments are constructed are shown as thick black curves inside the structure. The list of units: $\{\{\mathrm{R}, \mathrm{R} 2, \mathrm{~L}, \mathrm{R} 2, \mathrm{~L} 2, \mathrm{R} 2, \mathrm{R}, \mathrm{L}, \mathrm{R} 2\},\{\mathrm{R}, \mathrm{L}, \mathrm{R}, \mathrm{L}, \mathrm{R} 2, \mathrm{R}, \mathrm{R}, \mathrm{R} 2, \mathrm{R}, \mathrm{L} 2, \mathrm{~L}$, L2,L,R,R,R,R2,R2,R,R2,L2,R2,R2,R2,L2,R2\}, \{R,R,R,R2,L2,R,L,L2,L,R,L2,L,L2,L\}, $\{\mathrm{R}, \mathrm{R} 2, \mathrm{R} 2, \mathrm{~L} 2, \mathrm{R} 2, \mathrm{~L} 2, \mathrm{~L} 2, \mathrm{~L}, \mathrm{R} 2\},\{\mathrm{R}, \mathrm{R}, \mathrm{L}, \mathrm{L} 2, \mathrm{R}, \mathrm{R} 2, \mathrm{R}, \mathrm{L} 2, \mathrm{~L}, \mathrm{R} 2, \mathrm{~L}, \mathrm{~L} 2, \mathrm{R}, \mathrm{L}, \mathrm{L}, \mathrm{L}, \mathrm{R}\}\}$.

The structure of the main runs of the truss network generated for the given points is shown in Fig. 25.

\section{CREATING A NETWORK OF PATHS}

Finding a path or network of paths in the constrained environment is not a trivial problem. Each path must not collide with itself, other paths, and obstacles.

A possible procedure is outlined below.

1. Input data - positions of terminals and obstacles in plan as shown in Fig. 26.1. The terminals are numbered accordingly and the minimal number of junctions is calculated.

2. Triangulation of the plan and computing the positions of the centroids of the triangles as shown in Fig. 26.2.

3. Generating subsets of nodes as in Fig. 26.3.

4. Finding possibly the shortest segmented path - the minimum spanning tree (MST) of the subsets of the nodes on the grid constructed from the centroids of the triangles as shown in Fig. 26.4, so that:

4.1 None of the segments crosses another segment and none of the segments crosses an obstacle. 4.2 The sum of the lengths of all the segments is not more than a certain given value.

4.3 If it is not possible, an additional junction unit is introduced and the procedure runs from step 3.

5. Constructing the splines of the guiding paths from the segmented lines so that the minimal curvature is preserved due to the geometric characteristics of the truss- $\mathrm{Z}$ modules as shown in Fig. 26.5.

The algorithm for creating the truss structures for given paths operates on single paths as well as a list of sub-paths, and consists of the following steps:

1. All the segments of the truss containing two junction points are constructed (Fig. 27.1).

2. The junction units are completed by attaching the mirrored units (27.2).

3. These units become starting points for two half-runs of the remaining two paths (27.2) 


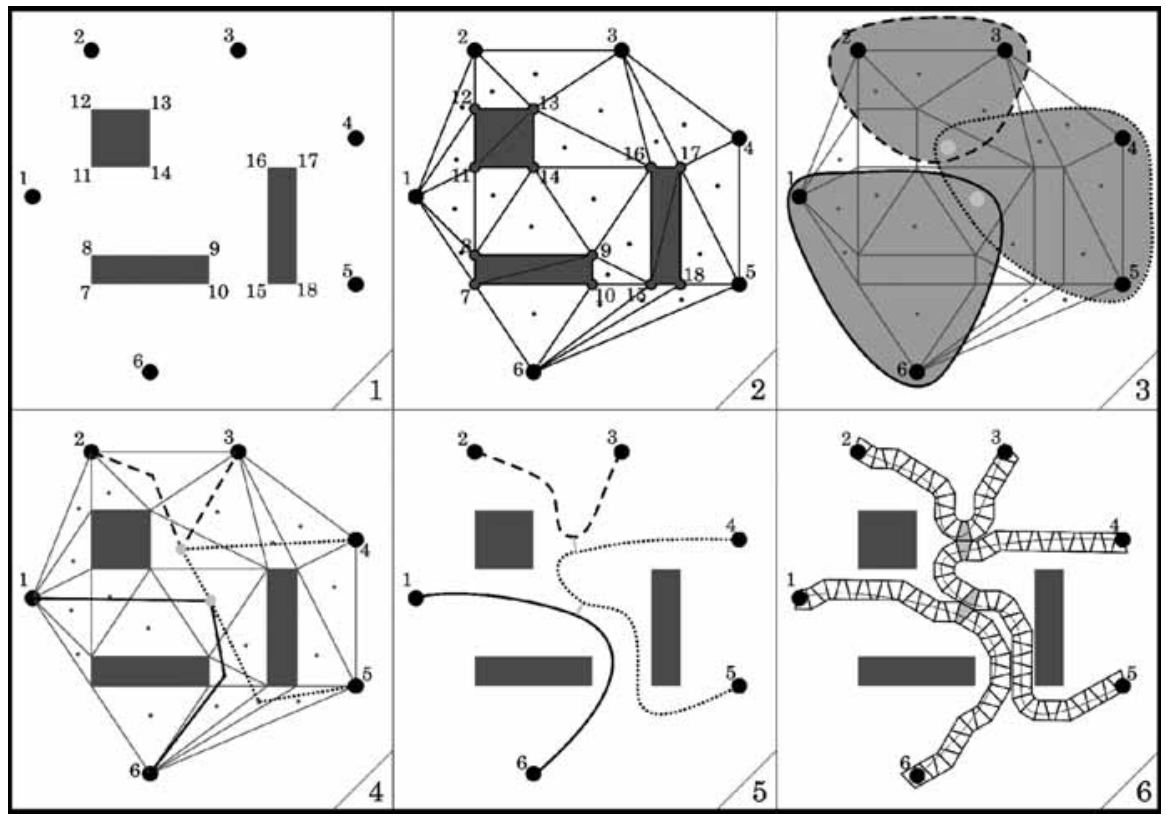

Figure 26: Schematic visualization of the general algorithm.

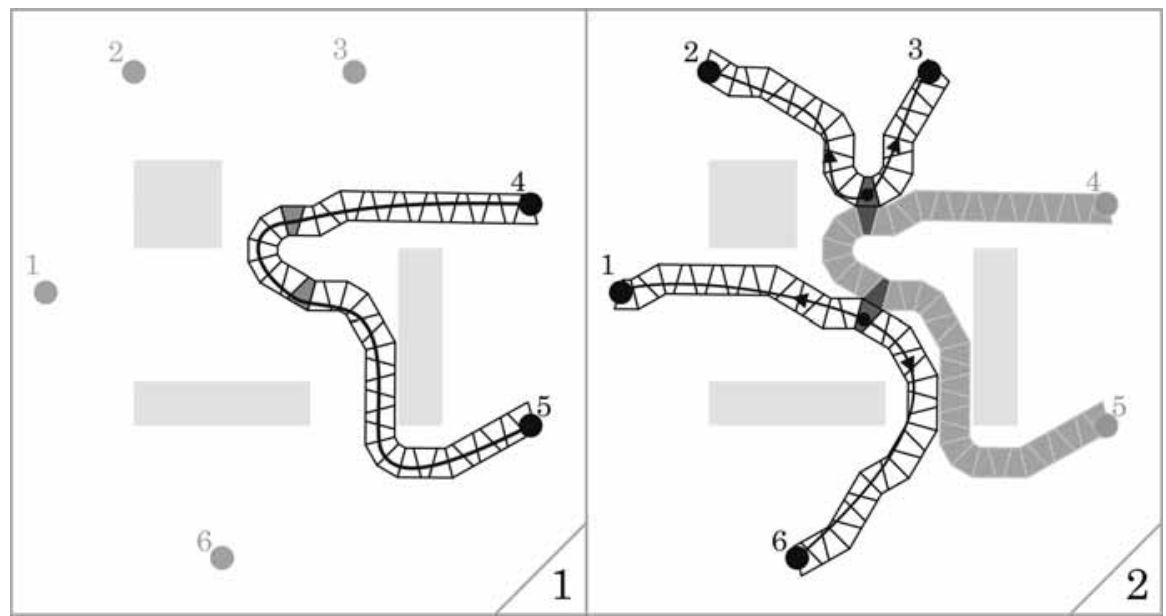

Figure 27: The sequence of constructing the segments of the truss network.

The procedure for creating a truss network presented above where the problems of first creating the 3D splines and next aligning of the truss modules to them was in fact not practical.

A method where structure is constructed directly, that is without the necessity for the guide paths is presented below.

\section{CREATING THE STRUCTURE WITH BACKTRACKING ALGORITHM}

This procedure is a combination of the Constraint Satisfaction Problem (CSP) where all the units must lie within the given area and the discrete local optimization - choosing the module which lies 
closer to the target. In this way locally optimal solutions are found, but the completed truss network is most likely not globally optimal as it is just one of the possible configurations. The problem in general is three-dimensional, but for clarity was reduced to the 2D plane, therefore instead of four possible variations of a unit there are only two: $\mathrm{R}$ (right) and L (left). An example of the procedure to create a truss network for six terminals in a constrained environment is shown in Table 2 . The truss modules can be placed within the white area only. The first (starting) terminal is chosen arbitrarily and the first segment of the truss connecting the first pair of consecutive terminals is constructed according to the following algorithm:

1. At each step a module ( $\mathrm{R}$ or $\mathrm{L}$ ) whose centroid is closer (minimization) to the target - the second terminal is chosen.

2. If any point of the truss module lies outside the allowed area (Constraint Satisfaction), the procedure steps back, switches the last unit $(\mathrm{R} \rightarrow \mathrm{L}$ or $\mathrm{L} \rightarrow \mathrm{R})$, and continues as in (1).

3. If any point of the truss module still lies outside the allowed area, the procedure steps farther back, switches the units and continues as in (2) until none of the modules lie outside the allowed area.

To construct the next segment of the truss, a branching unit is selected from the first segment. The branching can be executed by attaching an extra module to the longer side of a unit in the first segment. Therefore not all the segments are available for serving as a branching point- CSP. In Table 2.2 only L (left) modules indicated by dark gray can be used for branching toward terminals 3 and 4 . From the available segments, one is chosen so that the sum of the distances to the next terminals is minimal (local minimization).

\section{THE SUPPORTING STRUCTURE}

Besides the global stability, which can be considered separately, the structure is rigid due to the stiffness of the modules. Due to the limited strength of real materials, it is necessary to introduce a support system which is constructed from spatially rigid units of uniform length members - regular tetrahedra. Usually to avoid buckling, the supporting structure is constructed so that the load is carried possibly in the shortest way to the foundation. The proposed geometry of the supporting system based on tetrahedron may seem less intuitive, but with the use of a single unit, it allows the building of supporting elements in any direction (within certain accuracy) and even permits 'going around' obstacles. Although this is not a biomimetic project since it does not mimic any biological forms or mechanisms, the resemblance to natural processes is worthy of mention. Like many structures in Nature, the same element, agent, or unit in this case, is simple and at the same time universal enough to be used in a variety of ways $[14,15]$. The construction of the supporting structure is based on the algorithm for the single path segments of the truss. All except the first two elements of the support are made of regular tetrahedra with the length $a$ as shown in Fig. 28. First, at the selected truss module a non-regular tetrahedron is constructed with the three points of the truss unit as the base. Newly added elements have always length $a$. The third tetrahedron added in this procedure is already a regular one and so are all the following ones. As with the main truss, it is constructed along a given guide path. The algorithm has analog parameters $u$ and $b$ and chooses one of three possible orientations of the next tetrahedron.

The selection of the points for the support is based on the following rules:

1. The maximum stress: the maximum span (number of unsupported modules) is limited to a given value, for example every $10^{\text {th }}$ unit must be supported as shown in Fig. 29.1.

2. Structural stability: the supports are placed to maximize the balance of the truss (29.2).

3. The maximum eccentricity is limited to a given value as shown in Fig. 29.3. 
Table 2: The truss network procedure for an example with six terminals at constrained environment.

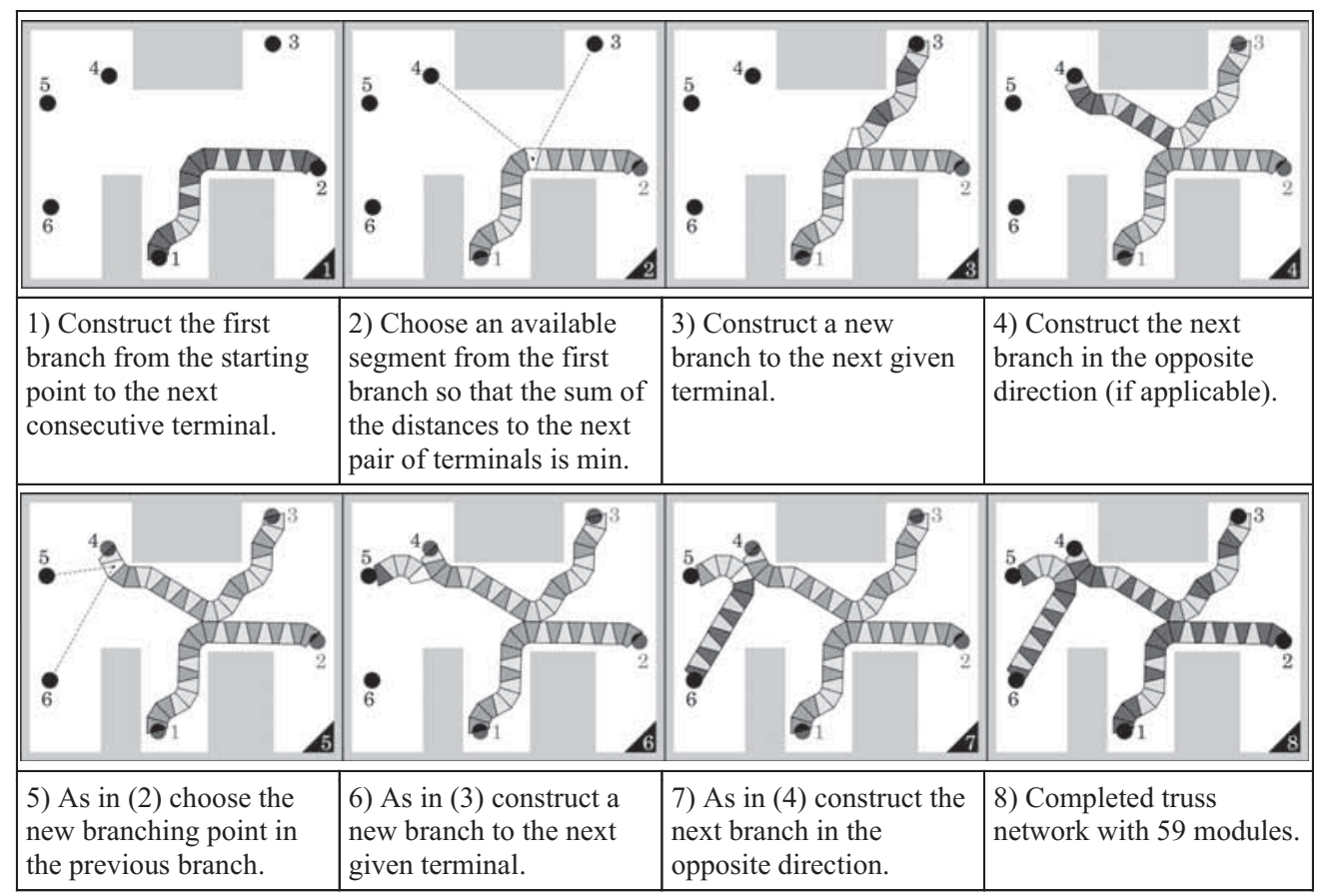

\section{THE GLOBAL OPTIMIZATION OF A TRUSS NETWORK}

The truss is modular and one network configuration differs from another by the way of connecting the units, therefore discrete optimization methods can be applied [16]. Although the number of possible combinations of the units is finite, it can easily become extremely large, thus heuristic methods are also considered, for example, a genetic algorithm. The configurations presented above are possible allowable solutions for given terminals and constraints. Since the sizing of the modules is not subject to optimization, the topology and shape of the modules are given - it is not a typical structural optimization problem [17]. The geometry of the truss network, however, can be optimized for various objective functions, for example, the minimal network distance. The network distance is the sum of all traverse lengths connecting every pair of terminals. An example of two networks with different network distances is shown in Table 3.

The truss system is composed of $3 \mathrm{D}$ modules, thus the number of possible combinations is always finite, therefore, the global optimization can be done by an intensive search. However, since there are four possible ways of connecting two units (R, R2, L, L2), the number of possible configurations for a single run of the truss grows exponentially: $4^{n}$, where $n$ is the number of units.

For example, in the case of the single run of the truss from the Fig. 23 with 33 units, the number of possible configurations are 73,786,976,294,838,206,464. For multiple branching the total number of possible configurations can be expressed as:

$$
\prod_{i=1}^{s} 4^{u_{i}} u_{i}
$$




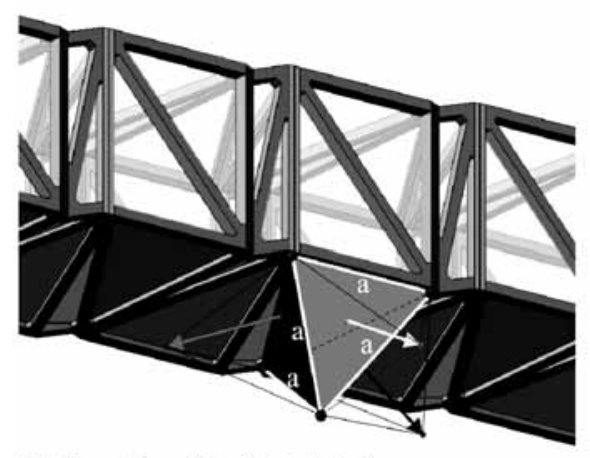

A bottom view of the first tetrahedron

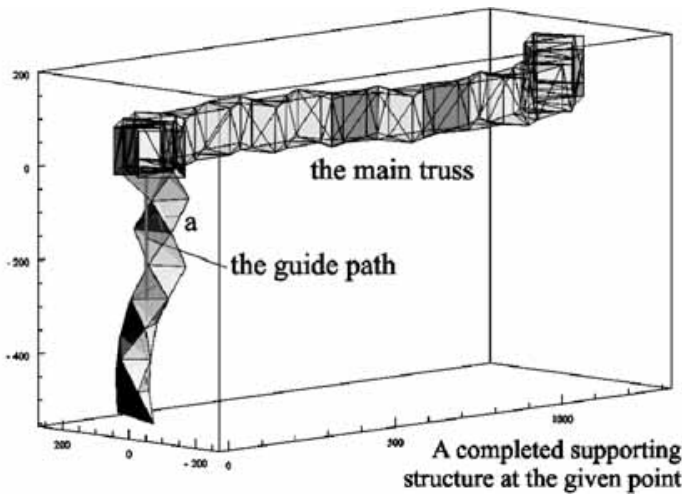

Figure 28: Isometric views of the supporting structure. On the left: there are three possible directions in which the next tetrahedron can be added at every step. On the right: a single support constructed along the given guide path.

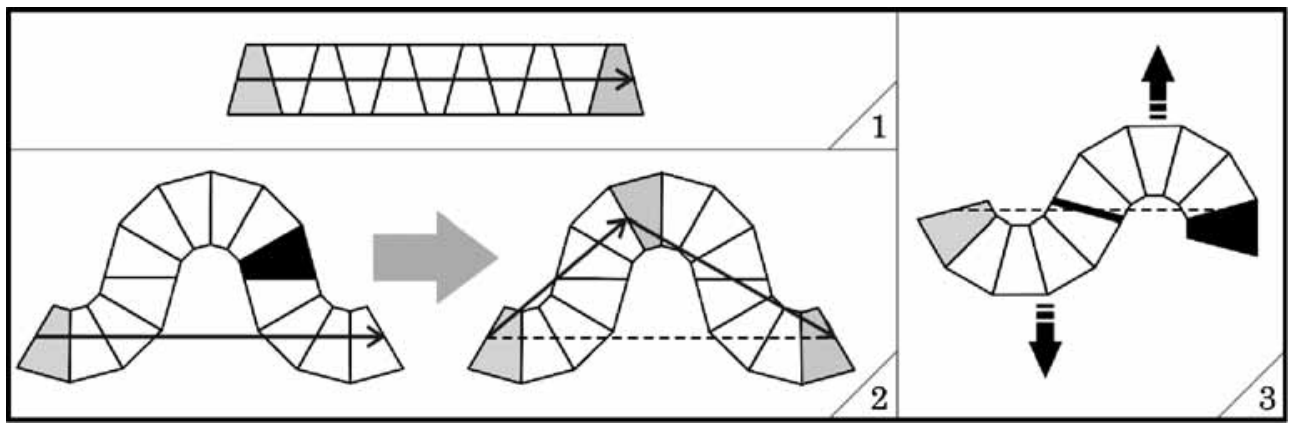

Figure 29: Top view: the placement of the supports: (1) the maximum span constraint, (2) stability, (3) eccentricity - the connection with maximum stress is indicated by a black thick line.

where

$s$ is the number of segments of the truss, $u_{i}$ is the number of units in the $i^{\text {th }}$ segment.

Therefore the number of all possible configurations of the example from the Table 3 (the left drawing with three segments connecting: terminals 1-2 with 21 units, terminals 3-4 with 23 units and 5-6 with 15 units) equals: $21 \times 4^{21} \times 23 \times 4^{23} \times 15 \times 4^{15}=240756420736542887479702053793$ $2774113280 \approx 2.4 \times 10^{39}$

This shows that the global optimization of the truss network is a difficult combinatorial problem which could not be solved with conventional and/or stand-alone computational tools [18]. An implementation of a heuristic method is rational - in this case a genetic algorithm.

\section{GENETIC ALGORITHM: THE TRUSS GENOTYPE}

The truss network can be encoded in a genotype as shown in Fig. 30. Such a code can be uniquely decoded into a phenotype and evaluated against structural requirements, for example whether the truss overlaps with any objects or intersects with itself or against an evaluation function, for example the distances of the 'leaves' (the last units in the truss segments) to the given terminals. 
Table 3: Two truss networks with 59 units.

The truss network produced by the backtrack More efficient network (minimized network algorithm (network distance: 335 ) distance: 318 )
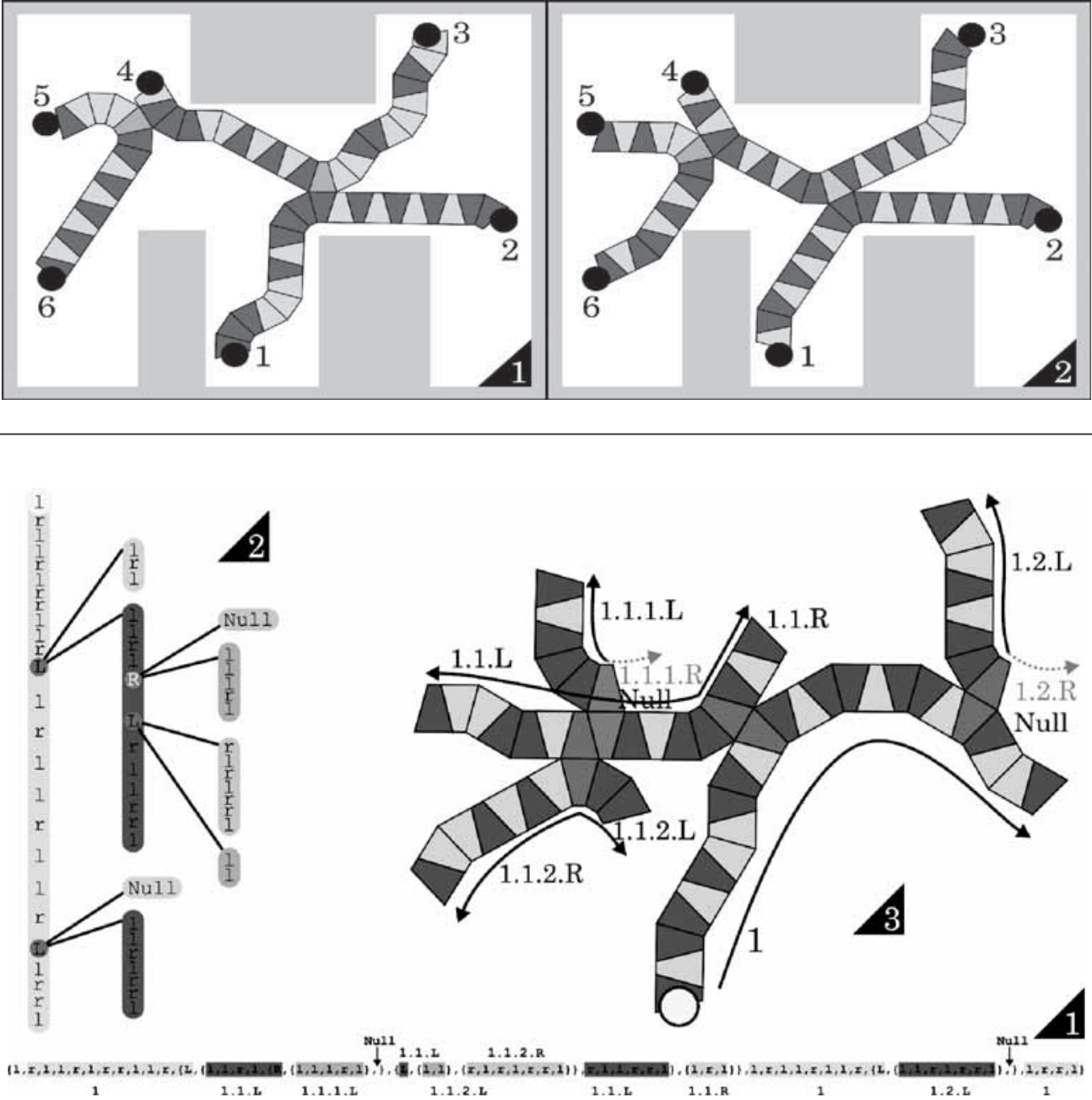

Figure 30: An example of encoding of a truss network: 1) a genotype, 2) graphic visualization of a genotype, 3) a phenotype.

Arrows in the Fig. 30 explain the naming convention for the units, which is relative to the branching point.

\section{GENETIC OPERATIONS}

The genotype of the truss can be subject to genetic operations: mutation and crossover as shown in Fig. 31.

The verification of the feasibility of the individual algorithm [19] is done by a logic operation of checking if all the geometrical constraints are met. Currently the penalization of infeasible 


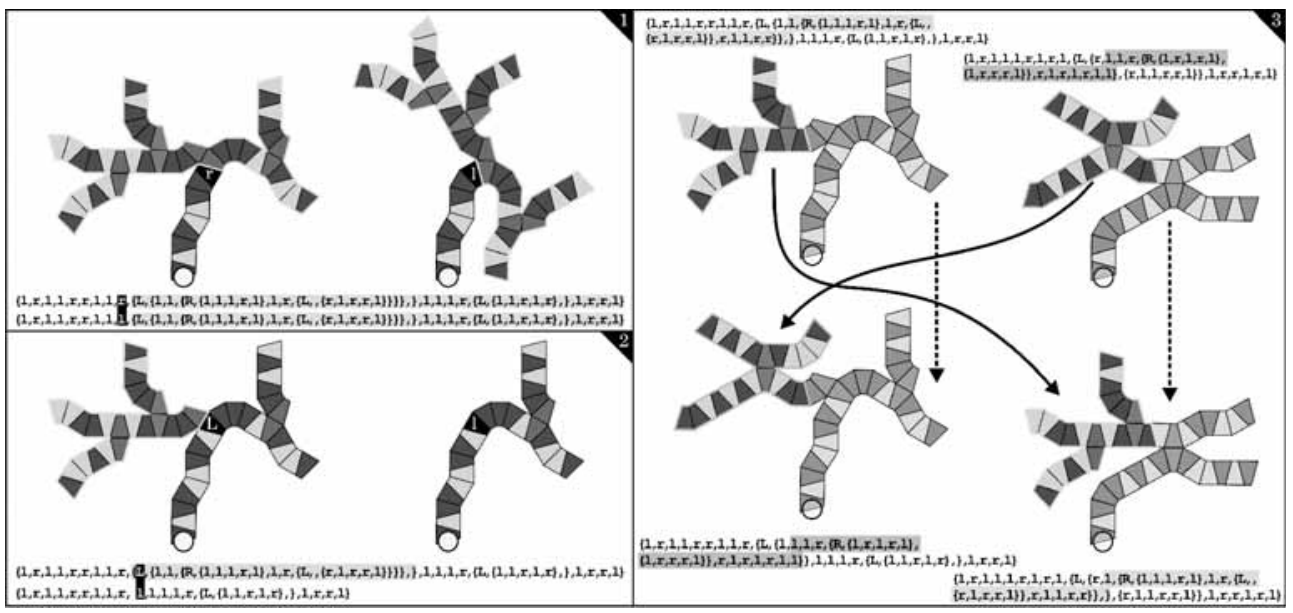

Figure 31: Examples of genetic operations and resulting phenotypes. (1) Mutation of a gene: $r$ (regular right module) $\rightarrow 1$ (regular left module); as result a part of the truss is reoriented. (2) $\mathrm{L} \rightarrow 1$ (a branching left module becomes a regular left module, as a result a whole branch disappears). (3) A crossover.

individuals is done by rejection. Although repairing of an infeasible individual is an interesting alternative, at the present the global optimization always starts from a generation based on an initial individual produced by the backtrack algorithm and which is always feasible. Therefore in practical examples it is always possible to avoid the situation where the initial population contains only infeasible individuals [20].

\section{OPTIMIZING THE TRUSS WITH SUPPORTS: A SELF-ADAPTIVE ACO}

All the methods of creating and further optimizing the truss network did not consider the problem of supports. In smaller examples the issue of locating the supports is usually not so difficult and in very small examples is not even necessary. However, for larger projects it becomes a challenging issue and the procedure given above may not be sufficient. It is conceivable that in the first step the main structure is constructed and in the second step the supports are added. There may be situations where constructing a support will not be possible due to collision with obstacles, and also with runs of the truss or other supports. In such a case the main truss should be modified to the worse allowable configuration and the attempt to add support restarted. The process should be reiterated until a satisfactory solution was found. It is however not an elegant solution, and due to computational complexity may not give results in a reasonable time. An interesting alternative would be actually constructing the supports along with the main structure of the truss. A method that seems appropriate is a self-adaptive ant colony optimization (ACO), however, it has not been implemented.

\section{CONCLUSIONS}

The concept of modular truss-Z system demonstrates unprecedented potential for creating reconfigurable structural networks:

- Robustness: In case of failure of a part of the truss or change of functional requirements, certain units can be replaced or rearranged without affecting the rest of the structure. 
- Re-use: The modules can be disassembled after a certain period and reconfigured into an alternative configuration.

- 'Flexibility': Some segments of the truss can be connected by revolute joints instead of rigid joints to allow a partial displacement (for example in seismic areas) as shown in Fig. 32.

- The modularity of truss-Z allows for inexpensive mass production and thus to make it widely available. There are countless possible applications such as linkages between buildings, overpasses, playgrounds, visitor ramps, etc.

- Since the modules are universal, they need to be dimensioned for the 'worst' possible configuration of the structural loads. This results in over-dimensioning of particular members, and therefore, an increase of the overall weight. It is also conceivable however, that advanced materials with higher strength-to-weight ratio can be used, but due to the mass-production, the cost can be minimized.

The uniformity of the modules generates the diversity in emergent forms reminiscent of those of the natural systems. Although truss- $Z$ does not mimic any naturally occurring phenomenon, its engineering oriented pragmatism could also be interpreted as an underlying biomimetism:

- Adaptivity: The truss system does not have any preferred direction and a truss network can be created virtually in any environment. There is, however, certain anisotropy due to the anthropocentric
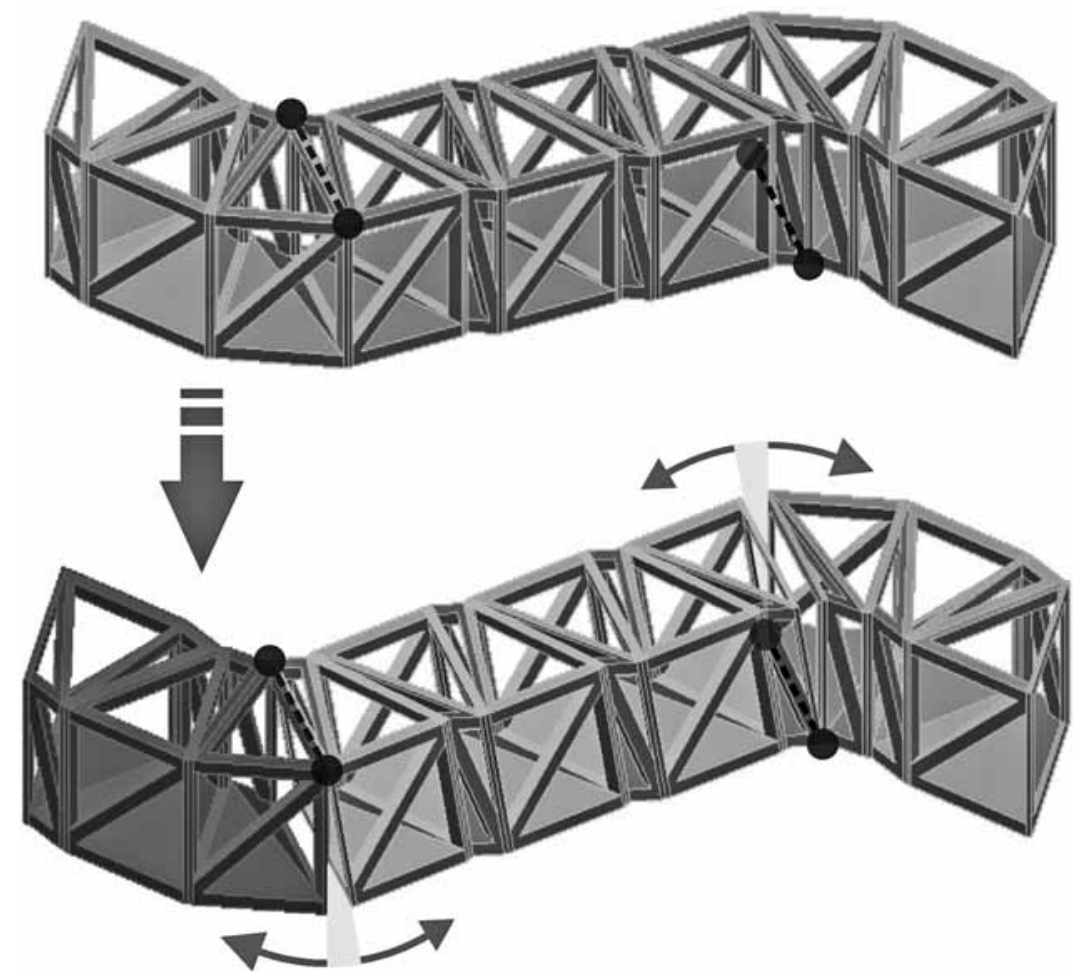

Figure 32: The truss- $\mathrm{Z}$ can be designed so that parts of it can be subject to displacement. The left part of the truss has dropped, for example due to a seismic movement. The revolute joints indicated by black dots allowed for safe displacement of the truss without causing damage. 
nature of this design it is meant for pedestrians, therefore, there is a distinction between vertical and horizontal geometrical characteristics.

- Modularity: A high spatial complexity can be achieved by assembling only two types of modules. Although in biological modular/cellular structures, the morphological diversity of elements that have the same topology is usually much greater.

- Morphogenesis: Although the system offers enormous diversity of shapes as shown in Figs. 2 and 17 , there is a strong connection between the shape of the unit and the shape of the whole structure.

- Biomimetic optimization: Global optimization by genetic algorithm was briefly described; encoding was explained and genetic operations outlined. The problem of supports, which makes the problem significantly more difficult, was also addressed and a self-adaptive ant colony optimization [21], which is a more recent biomimetic heuristic, was suggested as the optimization method. Another recently introduced method that seems appropriate for this problem is the great deluge method [22]. In the case of large truss networks, either with or without supports, "parallelization' seems a natural way of splitting the computational effort among many computers. Such an application has already been documented for optimization of steel structures with simulated annealing [23].

Certain practical problems such as model fabrication as well as full-scale manufacturing issues were addressed. In these processes Boolean operations such as subtraction or union of elements were used to a large extent - actions that can practically be performed only on a 'virtual', computer model.

\section{ACKNOWLEDGEMENTS}

This is part of a postdoctoral project grant-funded by the Japanese Society for the Promotion of Science. The research is titled "Improvements of the Seniors' Quality of Life through Application of Innovative Computational Systems (Accessibility, Ergonomics and Housing \& Living Environment)".

\section{REFERENCES}

[1] Spuybroek, L., NOX: Machining Architecture, Thames \& Hudson: London, England, pp. 142-157, 2004.

[2] Spuybroek, L., The Architecture of Variation, Thames \& Hudson: London, England, pp. 127-129, 2009.

[3] "Allround Modular Truss System" by Wilhelm Layher GmbH \& Co. KG, available at www. layher.co.nz/scaffold-project-allround-modular-truss-system.html.

[4] Modular truss systems: (US Pyatents 5964068, 5826384, 7347030, 5390463).

[5] Daily, C., Lees, D. \& McKitterick, D., Truss Structure Design, United States Patent and Trademark Office, Alexandria, VA, USA, 6076324, 1997.

[6] Staib, G., Dörrhöfer, A. \& Rosenthal, M., Components and Systems: Modular Construction Design, Structure, New Technologies, Edition Detail: Munich, Germany, 2008.

[7] Bowman, R., An Introductory Guide to the Slip Resistance of Pedestrian Surface Materials, Strathfield, NSW: Standards Australia; Wellington: Standards New Zealand, 1999.

[8] Billington, M.J., Bright, K.T. \& Waters, J.R., The Building Regulations: Explained and Illustrated, Wiley-Blackwell: Oxford, England, 2007.

[9] Terzidis, K., Algorithmic Architecture, Architectural Press: Oxford, England, p. 44, 2006.

[10] Fox, B., Rapid Manufacture in the Aeronautical Industry. Rapid Manufacturing: An Industrial Revolution for the Digital Age, eds. N. Hopkinson, R.J.M. Hague \& P.M. Dickens, John Wiley and Sons: Chichester, England, 2006. 
[11] Corke, G., Rapid Prototyping for Architecture. Prototype, EDA Publications: London, England, 2006.

[12] Kudless, A., Oxman, N. \& Swackhamer, M., Rapid Prototyping and Rapid Manufacturing at Foster + Partners. Acadia 2008 Proceedings of the 28th annual conference of ACADIA, 2008.

[13] Zawidzki, M., An algorithm for constructing a truss network with the modular truss-Z system for pedestrian traffic in a 3D environment. Design \& Nature V, Comparing Design in Nature with Science and Engineering, eds. C.A. Brebbia \& A. Carpi, WIT Transactions on Ecology and the Environment: Ashurst, England, 138, 2010.

[14] Jeronimidis, G., Bioinspiration for Engineering and Architecture: Materials - Structures Function, Proceedings of the 28th Annual Conference of the ACADIA, Association for Computer Aided Design in Architecture: Minneapolis, 2008.

[15] Bar-Cohen, Y., Biomimetics Biologically Inspired Technologies, Taylor \& Francis Group: Boca Raton, FL, USA, p. 230, 2006.

[16] Zawidzki, M. \& Nishikawa, I., Discrete optimization of modular truss network in constrained environment, Proceedings for CJK-OSM6: 6th China-Japan-Korea Joint Symposium on Optimization of Structural and Mechanical Systems, Japan Society of Mechanical Engineers: Kyoto, Japan, 2010.

[17] Kicinger, R., Arciszewski, T. \& De Jong, K.A., Evolutionary computation and structural design: a survey of the state of the art. Computers \& Structures, 83(23-24), pp. 1943-1978, 2005. doi: http://dx.doi.org/10.1016/j.compstruc.2005.03.002

[18] Saridakis, K.M. \& Dentsoras, A.J., Soft computing in engineering design - A review, Advanced Engineering Informatics, 22, pp. 202-221, 2008. doi: http://dx.doi.org/10.1016/ j.aei.2007.10.001

[19] Richardson, J.T., Palmer, M.R., Liepins, G. \& Hilliard, M., Some Guidelines for Genetic Algorithms with Penalty Functions, Proceedings of the Third ICGA, Morgan Kaufmann: San Francisco, CA, USA, pp. 191-197, 1989.

[20] Michalewicz, Z., Dasgupta, D., Le Riche, R.G. \& Schoenauer, M., Evolutionary Algorithms for Constrained Engineering Problems, Computers \& Industrial Engineering Journal, 30(2), pp. 851-870, 1996. doi: http://dx.doi.org/10.1016/0360-8352(96)00037-X

[21] Talbi E., Roux O., Fonlupt C. \& Robillard D., Parallel Ant Colonies for Combinatorial Optimization Problems, IPPS/SPDP Workshops: pp. 239-247, 1999.

[22] Dueck, G., New optimization heuristics: the great deluge algorithm and the record-to-record travel, Journal of Computational Physics, 104, pp. 86-92, 1993. doi: http://dx.doi.org/10.1006/ jcph.1993.1010

[23] Park, H.S. \& Sung, C.W., Optimization of steel structures using distributed simulated annealingalgorithm on a cluster of personal computers, Computers and Structures 80, pp. 1305-1316, 2002. doi: http://dx.doi.org/10.1016/S0045-7949(02)00073-1 